\title{
Outsourcing and structural change: shifting firm and sectoral boundaries
}

\author{
Sandro Montresor* Giuseppe Vittucci Marzetti
}

\begin{abstract}
The paper aims at investigating the structural change implications of outsourcing. In trying to bridge the organizational/industrial and the sectoral/structural analysis of outsourcing, it discusses the rational and the methodological pros and cons of a "battery" of outsourcing measurements for structural change analysis. Their functioning is then illustrated through a concise application of them to the OECD area over the ' $80 \mathrm{~s}$ and the early '90s. A combined used of them emerges as recommendable in checking for the role of outsourcing with respect to that of other structural change determinants.
\end{abstract}

\footnotetext{
${ }^{*}$ Corresponding author. Address: Department of Economics, University of Bologna, Strada Maggiore 45, 40125 Bologna, Italy, Tel.: +39 051 2092651, Fax: +39 051 237002, E-mail: montreso@spbo.unibo.it

Keywords: Outsourcing; Input-output analysis; Vertical integration; Manufacturing

JEL Classifications: D230, D570, L160, L220, L240, L600, O140
} 


\section{Introduction}

Outsourcing has recently become a "hot-topic" of several economic disciplines dealing with the firm, such as industrial organization, labour microeconomics, industrial relations and operation management, just to mention a few ${ }^{1}$ Accordingly, cases for and against outsourcing are numerous and heterogeneous, depending on the specific approach which is adopted.

This upsurging interest for outsourcing processes at the firm level has also had an important cross-disciplinary fertilization. For example, a "new" strand of trade theories has developed on the basis of its "fragmentation" effects (e.g. Kohler, 2004, Jones and Kierzkowski, 2001). Quite surprisingly, instead, the new wave of outsourcing studies has not been accompanied by an as enthusiastic revival of one of the economic fields which for first recognized its relevance: that is, structural change analysis.

More than 20 years ago already, Momigliano and Siniscalco (1982b), among others at that time (e.g. Stanback, 1979| Ginzberg and Vojta, 1981; Gershuny and Miles, 1983), recognized that the externalization of production activities from manufacturing firms to specialized producers of business services represented, also and above all, a change in the relative weight of the sectors of an economic system, in terms of both production output and employment. But, despite these seminal contributions, the structural change implications of service outsourcing have remained since then relatively neglected. On the one hand, the increasing availability of firm micro-data and the extraordinary development of firm surveying techniques have made the analysis of its impact on the firm boundaries dominant with respect to that on the boundaries of manufacturing sectors. On the other hand, the reference to the "establishment" as the unit of analysis for building up input-output tables has marginalized its interpretative role of a phenomenon which is claimed to occur at the firm level.

This is unfortunate, as the role of service outsourcing in explaining the structural change of economic systems is quite apparent. Indeed, the externalization of business services undertaken by manufacturing firms, while (or rather than) decreasing the industrialization degree of one economy, determines a reshaping of the sectoral boundaries between manufacturing and (business) services.

However, quite recently, the increasing pervasiveness of outsourcing has spurred some researchers to reconsider the role that, along with technological change and changes in demand, the kind of organizational change entailed by outsourcing has had on the economic restructuring of developed countries (Dietrich, 1999, McCarthy and Anagnostou, 2004). More precisely, these studies have tried to "decompose" the changes occurred over time in input-output tables data, with the aim of disentangling the relative weight of demand-side and supply-side factors in driving economic restructuring. In fact, these studies generally conclude that the "deindustrialization" arguments that have been used, for example, in accounting for the economic restructuring of Europe from the '70s to the '90s, have largely overlooked the extent of outsourcing processes. In so doing, they add, conventional economic views would have underestimated the actual importance and contribution of manufacturing to GDP.

In trying to get rid of such a bias, these studies attempt to bridge the

\footnotetext{
${ }^{1}$ For a critical survey of the different industrial approaches to national and international outsourcing see Spencer (2005). For a more general account of the issue in economics see instead Montresor et al. (2006).
} 
industrial analysis of outsourcing with the intersectoral one of structural change. More precisely, they propose to refer to some sectoral "proxy" of outsourcing to be used along with sectoral proxies of other demand and supply factors of structural change, and to deal with them simultaneously.

This paper tries to analyze this conceptual bridge from a methodological point of view. At the outset, it discusses its inspiring rational more in depth, along with its theoretical background (Section 2). The methodological problems which emerge in the bridging are then spelled out (Section 3). At first, a battery of indicators is surveyed which could be used to detect traces of outsourcing in what could be otherwise considered "simple" tertiarization (Section 4). Their functioning and interpretative power is then showed through an illustrative and concise empirical application to a set of OECD countries along the '80s and the '90s (Section 5). Section 6 concludes.

\section{Theoretical background}

In organization economics outsourcing is usually dealt with under the "firmboundaries" agenda. Indeed, it is considered as a process symmetric to the integration one ${ }^{2}$ through which the "vertical scope" of the firm shrinks rather than enlarging. Either because some transactions are "moved" from the firm to the market governance mechanism - following transaction cost economics or because monitoring costs are such to make external principal-agent relationships more effective - following incomplete contract theories - or because some activities are better carried out through external rather than internal resources and competences - following the resource-based view (Montresor et al., 2006).

Associating outsourcing to just a shrink of the firm boundaries could however be contrasted by looking at the firm as an "open system", whose boundaries integration and outsourcing would rather make, respectively, less and more "permeable" to other organizations and, more in general, to market mechanisms (Jacobides and Billinger, 2005). Indeed, some have argued that outsourcing, through the partnerships, collaborations and agreements which it often entails, would have stimulated the firms to become "extended enterprises" (McCarthy and Anagnostou, 2004) or, similarly, "network firms" (Antonelli, 1988).

Sticking to one or the other interpretation has important implications on the nature of the shifts that outsourcing determines in the boundaries of those sectors in which the relevant firms operate. Using a more accurate jargon, outsourcing turns out to have in the two cases different structural change implications. The fact that, for example, a textile firm outsources its machinery maintenance to a specialised service firm, according to the first interpretation just alters, namely diminishes, its economic contribution to manufacturing and, in turn, the economic contribution of manufacturing to the economic system: putting it simply, service outsourcing would induce nothing but a "tertiarization" effect. Following the second interpretation, however, the same outsourcing

\footnotetext{
${ }^{2}$ For this reason, it is often referred to simply as "disintegration" or "externalization". To be sure, in some economic disciplines, namely in business economics, outsourcing is distinguished from other externalization processes of the firm by looking at, for example, the nature and the characteristics of the underlying obligations, the strategic value of the assets involved, etc. In the present paper however, at the risk of being somehow inaccurate, we will treat externalization, disintegration and outsourcing as synonymous.
} 
operation would rather entail a restructuring of the textile sector, and of manufacturing in general, following which its contribution to the economic system is actually changed in nature rather than simply diminished. As Momigliano and Siniscalco (1982b) put it, much of what is called tertiarization should be better called integration of services in manufacturing or, possibly, of some manufacturing activities in other manufacturing activities.

In the light of the increasing resort that firms make to outsourcing strategies, capturing this particular kind of structural change, often amounting to an extension of manufacturing sectors into non-manufacturing sectors, has become extremely urgent. And as urgent has become the need of disentangling the role of outsourcing in explaining the deep structural changes that most of the developed economies have undergone over the last twenty years. The next sections of the paper aim to move in this direction, by debating some methodological issues (Section 3) and tools of analysis (Section 4), and by presenting some illustrative empirical evidences (Section 5).

\section{Outsourcing and sectoral input-output rela- tions}

In industrial organization, outsourcing is usually retained a process through which a certain firm "switches" from making a certain activity of its production process in-house to buying its outcome from an external contractor, typically another firm (Grossman and Helpman, 2002). Empirical evidences shows that increasingly more this switch occurs for those activities which are not part of the "core competences" of the firm, but rather ancillary ones, externalized to specialized suppliers of other industries: janitorial services and ICT are the most notable example (Abraham and Taylor, 1996). In these and other similar cases, on principle, one would expect that outsourcing, by involving an intersectoral relation, gets somehow reflected into a correspondent change in the relevant input-output table, which of such a kind of relations represents an increasingly more accurate map. In the following, we will refer to it as "intersectoral outsourcing".

Conversely, when firms outsource parts of their production process itself for example by contracting out the transformation of a certain intermediate input - the evidence of a change at the input-output level will presumably be less visible, as it amounts to an "intrasectoral outsourcing" relation, rather than an intersectoral one. Still, a certain correspondence between the two levels of analysis - that is, the firm and the sector level - could be looked for.

However, such a correspondence is just a spurious one, mainly for two methodological problems. The first one has to do with the unit of analysis for the construction of input-output tables ${ }^{3}$ Indeed, input-output tables are built up by measuring and adding, sector by sector, the deliveries of goods and services which occur between different "establishments", rather than between different firms, or enterprises, as such. In other words, the so-called "interestablishment deliveries" - that is, deliveries of goods and services between

\footnotetext{
${ }^{3}$ In general, intersectoral studies of outsourcing are quite "cavalier" on this point. In Tucker and Wilder (1977), Domberger (1998), Dietrich (1999) and McCarthy and Anagnostou (2004) for example, such a crucial issue is not even mentioned.
} 
establishments belonging to the same enterprise - are also accounted as total output of the production unit and thus recorded as either intermediate consumption or gross fixed capital formation by the receiving unit. Apparently, this would represent a serious obstacle in detecting outsourcing starting from input-output tables. Indeed, "data aggregation methods which assign various plants of a single company to different industries in effect ignore multi plant ownership and therefore result in data which are insensitive to major forms of vertical integration" (Woodrow Eckard, 1979, p.105): the comment, raised in an old but effective note on the empirical measurement of vertical integration, actually also applies to vertical disintegration.

The insensitivity of input-output tables to outsourcing is however not total and rather depends on the specific case. At the outset, the sensitivity is quite high in front of those outsourcing processes which occur when a certain establishment substitutes services and/or intermediate inputs provided by an establishment of a different firm, for those previously produced within the establishment itself ("pure outsourcing"). This happens, for instance, when a firm decides to outsource the janitorial services previously performed within each establishment to an external specialized service provider.

The sensitivity is definitively lower when services and intermediate inputs were previously provided to a certain establishment by another establishment of the same firm: indeed, the substitution, for the latter, of an establishment belonging to a different firm, could virtually leave the correspondent input-output deliveries unchanged but, it should be stressed, just in quantitative terms. Indeed, in terms of value, the substitution would certainly find an input-output manifestation because of the substitution of market prices for "internal prices" in evaluating the outsourced transaction. Such a transaction actually becomes more "permeable" to market mechanisms. One could think of a firm in the automobile industry that closes down a plant producing shock absorbers and starts buying them from specialized suppliers or sub-contractors. This is also the case of a firm which spins off one of its divisions.

A last case could instead generate a sort of "over-sensitivity", rather than insensitivity, of input-output tables to outsourcing. Such as when a certain firm creates, ex-novo, a new establishment for the provision of certain services and/or intermediate inputs to another existing establishment of its own. This could be the case of a firm establishing a plant for the internal provision of IT services, and such services were previously provided within each establishment of the firm, without involving inter-establishment deliveries.

Although it is certainly true that this difference in the unit of analysis poses some problems, it has to be noted that, if one deals with service outsourcing, as we actually do in the present paper, such a difference is not so crucial. Indeed, because of the particular nature of the output of such activities, that is neither storable nor transportable, the most frequent situation is probably the one in which, prior to outsourcing, services are provided within each establishment. One might think of janitorial or cleaning services. Firms do not usually set up separate establishments for the "in-house" provision of such services. In fact, implementing what is usually called an Activity-Based Costing and Management (ABCM), and thus keeping service costs under control, is usually one of the reasons for firms to outsource service provision $4^{4}$

\footnotetext{
${ }^{4}$ As pointed out by Domberger, "many private sector organizations, and most public sector
} 
However, it is also true that one should not exclude that, instead of resorting to outsourcing, firms could set up a separate establishment for the provision of such services. This is the case of over-sensitivity of input-output data already stressed: although, strictly speaking, this does not represent a case of outsourcing as such, changes in input-output relationships could assimilate it to other more proper cases of it. Notwithstanding, also in the light of its limited extent, accounting it as a special (and indeed "odd") case of inter-firm outsourcing does not appear totally misleading with respect to the inner rational of the process. Indeed, inter-establishment transactions, even if within the same firm, are more transparent than intra-establishment ones.

The second methodological limitation of an intersectoral analysis of outsourcing by means of input-output tables has to do with what is referred to as international "fragmentation" (e.g. Jones and Kierzkowski, 2001) and the distinction between its two main channels: international delocalization and international outsourcing. The former is intended as the set-up of a plant in a foreign country by a domestic firm, whereas the latter usually refers to a situation in which firms contract out parts of their production process to foreign firms ${ }^{5}$ Indeed, although phenomena of international fragmentation can be detected by referring to input-output tables of imported flows, it is not possible to distinguish at which extent it is due to delocalization rather than international outsourcing ${ }^{6}$ One again, although relevant, this problem is not so crucial for empirical applications, such as the present one, which intend to capture, rather than the international division of labour, the influence of outsourcing on the sectoral boundaries of an economy.

With these caveats in mind, in the following we discuss a "battery" of inputoutput indicators of outsourcing, at different levels of analysis (e.g. sectoral and subsystem) and with different interpretative power (e.g. direct and indirect).

\section{Outsourcing measurements for structural change analysis}

Once outsourcing has been meant as a structural change determinant, possibly substitutive or complementary with respect to other determinants at the sectoral level (such as industrialization and deindustrialization), identifying a consistent sectoral measurement for it becomes necessary, although problematic.

\footnotetext{
ones, cannot account for their internal costs of service provision on a disaggregated basis, that is, in terms of individual service" (Domberger 1998, p.47).

${ }^{5}$ To be sure, there is no clear definition of international outsourcing. Indeed, while someone uses the term as a synonym of international fragmentation, measuring it as the ratio of imported intermediate inputs to the total value of domestic production (e.g. Feenstra and Hanson, 1999, Glass 2004 Jones et al. 2005), someone else instead refers to "international partnerships" (e.g. Van Long, 2005), thus assuming a minimum level of relationship durability among the transactors.

${ }^{6}$ Input-output tables have been widely used in studies on international outsourcing in manufacturing sectors. In these works international outsourcing is measured as the ratio of imported to domestic intermediate inputs of each sector Campa and Goldberg 1997 Feenstra 1998 Feenstra and Hanson 1999). Another recent study by Hummels et al. (1998) deals with the issue of the actual complementarity between international production and international trade due to the increasingly important role played by vertical specialization. They use inputoutput data to calculate for each sector the amount of imported inputs embodied in exported goods.
} 
Indeed, because of the problems related to the unit of analysis (discussed in Section 3), such measurements cannot be taken for more than outsourcing proxies. Their interpretative power is however different, as we will show in the following.

\subsection{The sectoral indicators of service outsourcing}

The most straightforward way to capture the amount of service outsourcing made by the firms belonging to a certain manufacturing sector is, of course, looking at the correspondent intersectoral flows from the relevant input-output table. For instance, we could analyze the changes occurred over time in the intermediate business service transactions at constant prices ( $S E R V)$ made by manufacturing firms per unit of production $(Q)$, that is, for sector $i$ : $\Delta\left(S E R V_{i} / Q_{i}\right)$, where a positive variation could be a signal of outsourcing.

Although the most direct indicator, in using it we have to implicitly assume two hypotheses. First of all, returns to scale should be held constant, referring to a common but quite problematic assumption in input-output analysis of structural change. Second, we have to assume that technological progress does not significantly affect service technical coefficients in manufacturing sectors. In particular, if we are interested in cross-sectional structural comparisons, we should retain that this effect is the same across the compared countries.

Moreover, given that the present indicator is based on nothing but an inputoutput coefficient, we should also discount the fact that a change of it might be even provoked by cases of "intrasectoral outsourcing". Indeed, as we will clarify in the next section, this kind of outsourcing might decrease $S E R V_{i} / Q_{i}$ via an increase of the gross production of sector $i$ itself.

In trying to overcome these problems, one might want to use an alternative indicator of service outsourcing, suggested by McFetridge and Smith (1988), that is: the change in the ratio between the intermediate business service transactions of a certain sector $i\left(S E R V_{i}\right)$ and the value of wages and salaries of the same sector $\left(L A B R_{i}\right): \Delta\left(S E R V_{i} / L A B R_{i}\right)$. Indeed, as we will also argue in what follows, outsourcing usually implies a substitution of primary inputs, mainly labour, for intermediate inputs, so that a positive variation of the previous ratio could be signaling service outsourcing.

However, also to use this measure as an indicator of outsourcing we have to make an important implicit assumption: the price of business services in wageunits have to be stable over time. In making cross-section comparisons, for example, we have to assume a constant relative cost of labour across countries, an assumption which hardly holds true for economic systems with different levels of development. Moreover, the same indicator tends to vary, and thus become less reliable, whenever a change in the labour productivity of a certain sector is not properly reflected in the correspondent monetary wages.

Thus, also the present indicator, as the previous one, is just an imperfect indicator of service outsourcing at sectoral level. Both of them are affected by different phenomena, not all related to outsourcing. However, the "noise" by which they are affected can be deemed as less problematic when, and if, they both signal traces of outsourcing, while contrasting signals would recommend caution. 


\subsection{The input-output technical coefficients}

The effects that outsourcing brings about at sectoral level are not just limited to the direct ones associated to an increase of $S E R V_{i} / Q_{i}$. More in general, through any kind of outsourcing, intra-firm transactions, or better to say, "intra-establishment deliveries", which cannot be caught by national accounts and input-output data, actually shift outside the firm (the establishment) and thus become measurable by them. In other words, by shifting the boundaries of a certain establishment, outsourcing brings about an increase in the intermediate consumptions of the sector to which it belongs, which comes from organizational changes, and not from technological ones. More precisely, through this mechanism outsourcing affects the intermediate consumption, the total production and the value added of the sectors in which it occurs.

Of course, these effects are different depending on the sectoral classification of the establishments themselves. In what we called "intrasectoral outsourcing", the "outsourcee" and the "outsourcer" belong to the same sector: ceteris paribus, we can view outsourcing as increasing the intermediate consumption and the gross output of the same sector, while leaving its value added hardly affected. In what we called "intersectoral outsourcing", on the contrary, outsourcing involves units of production belonging to different sectors, such as in the case of producer services analyzed in the previous section: ceteris paribus, in the "outsourcer" sector, because of outsourcing, gross production can be viewed as unchanged, while its value added diminishes.

At the outset, these effects determine a change in the relevant input-output coefficients, that is in the correspondent elements $a_{i j}$ of matrix $\mathbf{A}$ defined as:

$$
\mathbf{A}=\mathbf{W} \hat{\mathbf{q}}^{-1}
$$

where $\hat{\mathbf{q}}$ and $\mathbf{W}$ stand for, respectively, the diagonalized vector of sectoral gross production and the matrix of intersectoral production flows.

And these changes can be read accordingly. When in a certain sector $j$ there are evidences of "intrasectoral outsourcing" processes, its gross output $\left(Q_{j}\right)$ increases, because the correspondent intrasectoral inflows $\left(w_{j j}\right)$ increase for accounting reasons. On the other hand, the inflows out of the main diagonal $\left(w_{i j}\right.$ with $\left.i \neq j\right)$ do not change. For this reason, outsourcing determines, first of all, a reduction in the extra-diagonal technical coefficients for sector $j$, that is, $a_{i j}$ (with $i \neq j$ ). In addition, as the sectoral value added, which is not affected by duplication, remains unchanged, the increase of $w_{j j}$ turns out to be greater than that of $Q_{j}$, because $Q_{j}$ is the sum of all the intermediate inflows plus the value added of the sector. Accordingly, outsourcing also makes the technical autocoefficients $a_{j j}$ increase. Summing up, "intrasectoral outsourcing" in a certain sector $j$ might be expected to determine a reduction in the technical coefficients $a_{i j}$ (with $i \neq j$ ) and an increase in the technical coefficient $a_{j j}$. Let us stress that this is due just to accounting reasons, not related to the production side (for a formal treatment see Appendix A.

These effects do not occur, instead, in the case of "intersectoral outsourcing", because the gross output of the "outsourcer" sector remains relatively stable. Therefore, disentangling organizational changes from technological ones becomes in this case nearly impossible. Additional information could however be obtained by looking at an important related sectoral ratio to which we will now turn. 


\subsection{The ratio between sectoral value added and gross pro- duction}

As we said in the previous section, outsourcing affects sectoral intermediate consumption, gross output and value-added, and these effects are different depending on the sectoral classification of the firms involved. In addition to a change in terms of input-output coefficients, outsourcing could also be expected to bring about a lower value added-gross production ratio in the sector of the outsourcer firm.

Indeed, this is a common idea in measuring the opposite phenomenon, as the value added-sales ratio has been quite often taken for a measure of vertical integration of both firms and sectors in industrial economics 7 Although quite common, however, in using it one should be aware of the fact that the value added-gross production ratio is affected by cyclical effects as well as sectoral crises. Indeed, being $Q_{i} \equiv V A_{i}+M_{i}$, where $Q_{i}, V A_{i}$ and $M_{i}$ stand for, respectively, the gross production, the value added and the intermediate consumptions of a certain sector $i$, the derivative of $V A_{i} / Q_{i}$ with respect to $V A_{i}$ is:

$$
\frac{\partial}{\partial V A_{i}} \frac{V A_{i}}{Q_{i}}=\frac{M_{i}}{Q_{i}^{2}}(>0) \text {. }
$$

Therefore, whenever there is a reduction in $V A_{i}$, with a constant $M_{i}, V A_{i} / Q_{i}$ diminishes. And the same ratio decreases also when the rate of decrease of $V A_{i}$ is greater than the rate of decrease of $M_{i}$, as it usually happens in sectoral crises, due to demand slowdowns. Indeed, whenever $g_{M i}>g_{V A i}$, where $g_{x}$ stands for the rate of change of $x$, we have that:

$g_{V A i / Q i}=g_{V A i}-g_{Q i}=g_{V A i}-\left(\frac{M_{i}}{Q_{i}} g_{M i}+\frac{V A_{i}}{Q_{i}} g_{V A i}\right)=\frac{M_{i}}{Q_{i}}\left(g_{V A i}-g_{M i}\right)<0$.

In order to discount, at least to a certain extent, these last factors, it is however possible to use average values of the same sectoral ratio over a sufficiently long period ${ }^{8}$ Although with some arbitrariness, due to the identification of the extent of this period, average $V A / Q$ sectoral ratios can be retained as indicators of sectoral vertical integration/disintegration, with important elements of complementarity with respect to the other analyzed indicators. In particular, with respect to an indicator that we will present in the next section, once we will have moved from a sectoral level of analysis, retained up to now, to a subsystem level of analysis.

It should be noted also that some economists have argued that such an indicator should just be used in intertemporal analyses, but not in cross-sectional comparisons, being biased by the fact that the index 'will be higher the closer the firm in question is to the raw materials source of the production chain' (Tucker and Wilder, 1977, p.83).

${ }^{7}$ The value added-sales ratio as a measure of vertical integration was firstly proposed by Stigler (1951) and then utilized in a seminal article by Adelman (1955). It was then used in a number of empirical studies for testing the shifts over time of vertical integration in manufacturing (e.g. Laffer 1969, Tucker and Wilder, 1977).

${ }^{8}$ To get rid of trends in profitability, Tucker and Wilder (1977) construct instead an alternative index, defined as $(V A-N$ et income-Income taxes $) /(Q-N e t$ income - Income taxes $)$. However, due to data availability, using this index usually shrinks the coverage of the set a lot. 


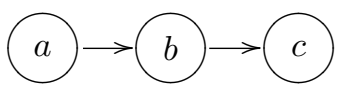

(a)

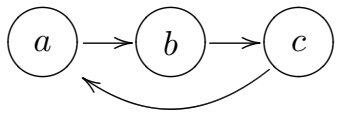

(c)

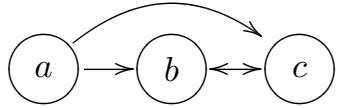

(b)

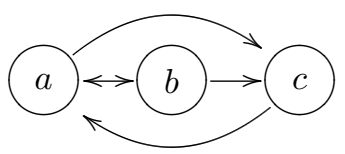

(d)

Figure 1: Examples of intersectoral linkages

The previous statement is however not guaranteed, and holds true just by assuming vertically integrated models of production, which quite often undervalue horizontal linkages among sectors 9 Indeed, thinking about an economic system as a "production chain" means regarding sectors as "boxes" put along an ideal line, moving from raw materials toward finished goods, in which there is a unique ranking of sectors resulting from their "proximity to raw materials". If such a ranking existed, then it would be true that the closer the sector firms belong to is to raw materials, the higher its value added will be compared with its gross production 10

However, if intersectoral linkages creates cycles among sectors, as it actually occurs, there is no ranking in terms of proximity to raw materials according to which sectors can be classified. More precisely, and using terms coming from graph theory, we could say that, if intersectoral linkages are such that sectors belong to one strong component, no ranking can be specified (Diestel, 2005).

In order to give an example, Figure 1 shows four possible patterns of linkages among sectors in a simple three sectors economic system. As shown by the Figure, in case (a) and (b) it is possible to rank the sectors. Indeed, in case (a) from sector $a$ one can move toward the remaining sectors, but the sector itself cannot be reached starting from one of the other two; from sector $b$ one can reach only sector $c$; from sector $c$ it is not possible to go anywhere else. Therefore in such a case the sectors are ranked as follows: $1-(a), 2-(b)$, $3-(c)$. Also in case (b) there is a ranking. Indeed, while from sector $a$ one can reach the remaining two, there is no way toward sector $a$ starting from $b$ or $c$. Accordingly, the ranking is: $1-(a), 2-(b, c)$. On the contrary, in the remaining

\footnotetext{
${ }^{9}$ For a discussion on vertically and horizontally integrated models of production see Baranzini and Scazzieri (1990)

${ }^{10} \mathrm{E} . \mathrm{g} .$, let us suppose there are only three sectors in the economy, each adding a value of 100 If sector $a$ produces its own output using just labour and non produced means of production, sector $b$ utilizes sector $a$ 's output as an input and the same does sector $c$ with sector $b$ 's output to eventually deliver its products to final demand, the value added-sales ratios of the three sectors will be as follows:

$$
\frac{V A_{a}}{Q_{a}}=\frac{100}{100}=1 ; \frac{V A_{b}}{Q_{b}}=\frac{100}{200}=0.5 ; \frac{V A_{c}}{Q_{c}}=\frac{100}{300}=0 . \overline{3} .
$$
}


two cases $(\mathrm{c})$ and $(\mathrm{d})$, , one can reach each sector starting from each other and no ranking can be therefore specified.

Strictly speaking, for having a ranking among sectors, the input-output coefficients matrix of an economic system should be decomposable, that is, reducible through elementary operations to a block triangular matrix; a condition which is rarely fulfilled. However, there could be sectors in which vertical linkages between different production processes are more prominent than horizontal ones, and the former still determine a bias when value added-gross production ratios are used. Notwithstanding, it is also true that, while this could be the case when a manufacturing sector is compared with an agricultural one, it is not probably so when the comparison is between two manufacturing sectors. Indeed, in the latter case horizontal linkages are far more important than vertical ones. Accordingly, no process can be viewed to be "closer" to the raw materials than another one and the value added-gross production ratio can be retained as a rather consistent indicator of vertical integration also in comparisons across sectors. What is more, the coexistence of vertical and horizontal linkage spurs the researcher to look for outsourcing measurements which are able to catch the whole complexity of the input-output relations of an economic system. As is well known, the concept of subsystem is an important reference point in this last respect.

\subsection{The weight of sectors in the relative subsystems}

The concept of "subsystem" (sometimes also termed "vertically integrated sector") is extremely useful when one wants to retain both direct and indirect relations in an economic system. 11

Following Momigliano and Siniscalco (1982a b), the concept can be expressed by referring to a matrix $\mathbf{C}$ in which each cell $c_{i j}$ measures the share accounted by sector $i$ in the total labour required by subsystem $j$ to produce the output needed to satisfy the final demand. Indeed, $\mathbf{C}$ is defined as:

$$
\mathbf{C}=\hat{\mathbf{l}} \mathbf{B}\left(\widehat{\mathbf{l}^{\prime} \mathbf{B}}\right)^{-1}
$$

where $\mathbf{l}^{\prime}$ is the row vector of labour inputs, the hat symbol is used to denote diagonalization and $\mathbf{B}$ is defined as:

$$
\mathbf{B}=\hat{\mathbf{q}}^{-1}(\mathbf{I}-\mathbf{A})^{-1} \hat{\mathbf{y}} .
$$

In (3) $\hat{\mathbf{q}}$ is the diagonalized vector of gross production, $\mathbf{A}$ is the matrix of technical coefficients calculated on the basis of domestic flows and $\hat{\mathbf{y}}$ is the diagonalized vector of total final demand. Each row of $\mathbf{B}$ adds up to 1 and shows "the shares of output of each branch which contribute to the different subsystems" (Momigliano and Siniscalco, 1982b, p.156) ${ }^{12}$

\footnotetext{
${ }^{11}$ The genesis of vertical integration can be traced back to Adam Smith. However, starting from the seminal notion of subsystem put forward by Sraffa $(1960)$, it was only in the late 60 s that the concept of vertically integrated sector was analytically studied by, among the others, Zaghini (1967) and Pasinetti (1973). Until the work of Momigliano and Siniscalco (1982b) the concept was mainly utilized in empirical studies on productivity, as those by Gossling (1972) and Gupta and Steedman (1971) and, more recently, by Milberg (1991).

12 It has to be noted that the elements of $\mathbf{C}$ turn out to be invariant to changes in relative prices as well as in final demand. The former property comes directly from the invariance to
} 
Each cell $c_{j j}$ of the main diagonal of $\mathbf{C}$ tells us which is the weight of sector $j$ on the correspondent subsystem in terms of labour, that is: the proportion of total labour, directly and indirectly needed to produce the output of a certain sector $j$, accounted by sector $j$ itself. Accordingly, $c_{j j}$ can be taken as an important proxy of the vertical integration and disintegration of sector $j$. If this sector were fully vertically integrated, i.e. if the production process turning non produced inputs into final goods took place entirely within the sector itself, this value would be equal to 1 . Conversely, the closer the value of the main diagonal cell is to 0 , the more the correspondent sector will be vertically disintegrated, the more outsourcing processes can be retained relevant for it 13

In a similar way, adding up, for each column $j$, the rows of the $\mathbf{C}$ matrix which refer to business services ${ }^{14}$ we obtain a measure of the integration degree of the same services in the correspondent manufacturing subsystem $j$. And also this indicator can provide us with important information in terms of outsourcing: the lower this sum, the less business services are integrated into the relevant manufacturing subsystem, the more business services outsourcing are presumable in place.

At this point we should remark that the cells of the $\mathbf{C}$ matrix can be taken as indicators of what should be called "system" integration, i.e. the integration that arises from the whole set of input-output relations occurring in the economic system. As it is determined by both technological and organizational factors, and not only specific to the sector under consideration, this system integration is different from that integration which is usually contrasted with outsourcing. Indeed, the values of $\mathbf{C}$ are affected by the different labour productivities and production techniques of the different sectors of an economy, as well as by the organization of their production processes ${ }^{15}$ Thus, changes over time in the values of $\mathbf{C}$ cells actually reflect all of these changes.

However, it is also true that this temporal analysis also brings out the impact of the reorganization of the production processes on the division of labour across the sectors of the different filières: to the extent at which it reduces the relative weight of a certain sector in the relative subsystem, outsourcing is thus one of the production reorganizations signaled by $\mathbf{C}$. Accordingly, firm's integration and system integration are strictly linked, though not coincident.

On the contrary, it can be proved that $\mathbf{C}$ is not affected by "intrasectoral

changes in relative prices of the $\mathbf{B}$ operator demonstrated by Rampa (1982). The latter, noted by us, results from the fact that each element in $\mathbf{C}$ works out sectoral shares in subsystems; thus, assuming constant returns to scale, shares are not affected by scale. Indeed, the generic element $c_{i j}$ of $\mathbf{C}$ can be expressed as follows:

$$
c_{i j}=\frac{h_{i} \alpha_{i j} y_{j}}{\sum_{i=1}^{n} h_{i} \alpha_{i j} y_{j}}=\frac{h_{i} \alpha_{i j}}{\sum_{i=1}^{n} h_{i} \alpha_{i j}}
$$

where $h_{i}, y_{j}$ and $\alpha_{i j}$ stand for, respectively, the labour input coefficient of sector $i$, the final demand of $j$ and the generic element of the Leontief inverse matrix.

${ }^{13}$ Although not explicitly considered in the above cited works, the elements in the main diagonal of $\mathbf{C}$ was used by Momigliano and Siniscalco (1984) in a subsequent work to measure the "error" standard sectoral analysis makes as it studies sectors in "relative isolation".

${ }^{14}$ The weight of business sector services in each subsystem $j$ is then measured by $\sum_{i=n}^{m} c_{i j}$, where $c_{i j}$ is the generic element of the matrix $\mathbf{C}$, and the rows from $n$ to $m$ correspond to the business services sectors of the same matrix.

${ }^{15}$ Keeping labour input coefficients constant, if the technical coefficient matrix is not decomposable, that is, if it cannot be reduced through elementary operations to a block triangular matrix, an increase in service expenditure in whatever sector causes an increase in the weight of services in each subsystem. 
outsourcing" phenomena (Appendix A contains the formal proof). Thus, the analysis of the changes over time in $\mathbf{C}$ cells does not point out organizational changes that occur entirely inside the sector itself, without involving across sectors reorganizations. E.g., if establishments classified in textiles externalize some activities to establishments belonging to the same sector, this change cannot be detected by changes in the values of $\mathbf{C}$, at least keeping the level of aggregation unaltered.

With this caveat in mind, the $\mathbf{C}$ matrix based indicators can be used as first, possibly rough, signals of outsourcing processes. It should be noted that, although absent in previous works on the issue (Momigliano and Siniscalco, $1982 \mathrm{a}$ b), the indexes related to subsystems can be built up by using not only domestic flows, but also total flows (domestic plus imported). In a world that is more and more integrated and pervaded by international outsourcing, it seems actually hard to defend the choice of leaving out foreign intermediate inputs in order to avoid the technical problems they entail. Indeed, when total input coefficient matrices are utilized in computing subsystem values, the theoretical meaning of the operation through which labour input coefficients are multiplied by the Leontief inverse becomes less clear. However, they can still be used by resorting to a more articulated interpretation of the deflation of the imported input coefficient matrix (M), for example, following Rampa and Rampa (1982) 16

Thus, instead of working out $\mathbf{C}$ as in Equation (2), it is possible to calculate it as follows:

$$
\mathbf{C}=\hat{\mathbf{l}} \mathbf{N}\left(\widehat{\mathbf{l}^{\prime} \mathbf{N}}\right)^{-1}
$$

where:

$$
\mathbf{N}=\hat{\mathbf{q}}^{-1}(\mathbf{I}-(\mathbf{A}+\mathbf{M}))^{-1}
$$

As before, $\mathbf{l}$ is the vector of labour inputs, $\mathbf{q}$ is the vector of sectoral gross productions, $\mathbf{I}$ is an identity matrix, $\mathbf{A}$ is the matrix of domestic inputs coefficients and $\mathbf{M}$ is the matrix of imported inputs coefficients ${ }^{17}$

Differently from Equation (2), in Equation (4) there is no reference to final demand, but this is not important given the proved invariance of $\mathbf{C}$ to changes in final demand.

\subsection{Summing up}

In closing the presentation of the outsourcing measurements for structural change analysis, it is worthwhile stressing that these indicators (or better to say prox-

\footnotetext{
${ }^{16} \mathrm{As}$ they argued: "If $m_{i j}$ is an imported inputs technical coefficient and $\bar{m}_{i j}^{0}=$ $\left(p_{m i}^{0}\right) m_{i j}\left(p_{j}^{0}\right)^{-1}$ is the associated expenditure coefficient at constant prices, the latter can be written as $\left(p_{m i}^{0} / p_{i}^{0}\right) p_{i}^{0} m_{i j}\left(p_{j}^{0}\right)^{-1}$. Thus $\bar{m}_{i j}^{0}$ can be seen as the quantity of domestic input $i$ needed to obtain the amount of imported input $i$ necessary to produce a unit of $j$ at the terms of trade which prevail in the base year $\left(p_{m i}^{0} / p_{i}^{0}\right) "($ Rampa and Rampa, 1982, p.318, our translation).

${ }^{17}$ By using the deflated $\mathbf{M}$ matrix in working out $\mathbf{B}$ as in Equation (3), and by premultiplying it by $\hat{\mathbf{l}}$, we obtain a matrix whose generic element can be seen, with respect to the imported part, as the labour needed for a "special" kind of international exchange, that is: the labour to produce the domestic commodities necessary to obtain the foreign ones used in producing the relative (subsystem) final good. Foreign commodities which are in turn obtained through an international exchange carried out at the import-export relative prices of the base year. Furthermore, when the total flows transaction matrix is used, instead of the domestic one, the invariance of $\mathbf{C}$ to relative price changes does not hold anymore, because $\mathbf{C}$ turns out to be affected by changes in terms of trade, so that matrices at constant prices should be used.
} 
Table 1: Expected variations of the sector/subsystem indicators in manufacturing sector $i$

\begin{tabular}{lllc}
\hline \multirow{2}{*}{ Event } & Level & Indicators & $\begin{array}{c}\text { Expected } \\
\text { variation }\end{array}$ \\
\hline Intersectoral disin- & Sector & $V A_{i} / Q_{i}$ & $-\Delta$ \\
tegration & & $a_{i i}$ & $-\Delta$ \\
& & $S E R V_{i} / Q_{i}$ (service outsourcing) & $+\Delta$ \\
& & $S E R V_{i} / L A B R_{i}$ (service outsourcing) & $+\Delta$ \\
\cline { 2 - 4 } & Subsystem & Vertical integration degree & $-\Delta$ \\
& & Business services integration (service & $+\Delta$ \\
Intrasectoral disin- & Sector & $V A_{i} / Q_{i}$ & $-\Delta$ \\
tegration & & $a_{i i}$ & $+\Delta$ \\
& & $S E R V_{i} / Q_{i}$ & $-\Delta$ \\
& & $S E R V_{i} / L A B R_{i}$ & $=$ \\
\cline { 2 - 4 } & & Subsystem & $=$ \\
& & Vertical integration degree & $=$ \\
\hline
\end{tabular}

ies) are among them inherently diverse, and all affected by a certain degree of inaccuracy. For this reason, they should be used, rather than alternatively, in a complementary way, by retaining their different signaling power (Table 1).

In so doing, their limitations could be mutually overcome, such as for example, when we compare the value-added/gross production ratio of Section 4.3 with the vertical integration degree of Section 4.4. On the one hand, while the vertical integration degree, calculated as the sectoral labour share of a sector in the relative subsystem, is not affected by phenomenona of disintegration that occur entirely within the sector, the same does not hold true with respect to the sectoral $V A / Q$ ratio, which instead tends to decrease for what we termed "intrasectoral outsourcing". On the other hand, the vertical integration degree of the sector is less influenced than the sectoral $V A / Q$ ratio by those "market power" factors which affect the translation of the different labour costs into prices. Indeed, if a sector is quite far from a perfectly competitive model, firms might impose a mark-up relatively high, and the sectoral $V A / Q$ ratio tends to rise. For these reasons, the two indicators should be used as complementary rather than substitute. And a similar argument holds true with respect to the other indicators, as we will show in the next section through an illustrative empirical application.

\section{An illustrative application to the OECD area}

In order to illustrate the actual functioning of the outsourcing measurements discussed in the previous section, we apply them in carrying out both a crosssectional and an inter-temporal analysis of the economic structure of some OECD countries over the '80s and the middle '90s. More precisely, because of data availability, we will refer to two different country sets: the OECD6, made up of Canada, Denmark, France, Japan, UK and US, over the '80s; the OECD18, that includes Australia, Canada, Check Republic, Denmark, Spain, 
Finland, France, Germany, Greece, Hungary, Italy, Japan, Korea, Netherlands, Norway, Poland, UK and US, with respect to the middle '90s (see Appendices $B$ and D.

Data availability also allows us to retain a sectoral disaggregation for manufacturing (including construction) of 14 sectors for the OECD6 over the '80s, and of 17 sectors for the OECD18 in the middle '90s (see Appendix E) 18

At the outset, we stress that such an application is just intended to be illustrative of the methodological pros and cons of the various indicators, rather than explorative of the economic structure and structural change of the OECD area 19 We also stress that, rather than following the presentation order of the outsourcing measurements, the application starts by looking for the most general traces of outsourcing, at the subsystem level, for then moving to more specific insights at the sectoral level.

\subsection{Searching for "system" traces of service outsourcing}

To start with, although a rough measurement, cross-country average values of the sectoral vertical integration degree and of the business services integration provide some interesting insights about those sectors which are "structurally" more disintegrated than others, and for which outsourcing could thus be more relevant.

Across the 18 OECD countries considered in the middle '90s, 5 are the sectors in which, on average, extra-sectoral labour contributions (direct and indirect) are particularly relevant (Table 22, ${ }^{20}$ However, when the role of natural resources intensity is discounted for, the number of the most disintegrated sectors narrows to 3: basic metals, chemical and transport equipment subsystems, for which, unlike the other two (i.e. food, beverages and tobacco, and coke, petroleum, and nuclear fuel) no manufacturing or agricultural sector out of the main diagonal plays a pivotal role.

Quite interestingly, these are also among the sectors in which production services have the greatest average labour weight in the middle '90s. More in general, the two rankings are quite similar, supporting our tentative interpretation of a relationship between vertical disintegration and integration in business services 21

Our structural analysis seems thus aligned with what other contributions find through case-studies at the firm level, in particular for transport equipments and chemicals (Domberger, 1998). As for basic metals, instead, the result is somehow counterfactual, having in mind the relative "closeness" to raw materials of the sector compared to the other manufacturing ones. However, the data show a prominent role of horizontal linkages over the vertical ones for manufacturing,

\footnotetext{
${ }^{18}$ In the definition of business sector services we have followed OECD conventions (50-74 ISIC Rev.3) (see Appendix C). In order to avoid, as much as possible, distortions coming from sectoral aggregation, calculations have been carried out at the maximum level of disaggregation, and then the results have been reaggregated as required.

${ }^{19}$ In this vein, the present application represents a selection of a more extended empirical work carried out on the same area (Montresor and Vittucci Marzetti 2006).

${ }^{20}$ In Table 2 sectors have been ranked by referring to total production input-output tables. However, the ranking remains substantially unchanged when the reference is to domestic production flows (the Spearman correlation index is as high as 0.941).

${ }^{21}$ The Spearman correlation index is 0.684 and becomes 0.798 when the two "resource intensive" sectors previously analyzed are not considered.
} 
Table 2: Vertical disintegration and business services integration per industrial subsystems - middle '90s - cross-country average values

\begin{tabular}{|c|c|c|c|c|}
\hline \multirow[b]{2}{*}{ Industrial subsystems } & \multicolumn{4}{|c|}{ Avg \% values } \\
\hline & $\begin{array}{l}\text { Vertical } \\
\text { disintegration }\end{array}$ & Rank & $\begin{array}{l}\text { Business } \\
\text { services } \\
\text { integration }\end{array}$ & Rank \\
\hline \multicolumn{5}{|l|}{ Low vertical integration } \\
\hline Coke, refined petroleum products and nuclear fuel & 9.9 & 1 & 35.8 & 1 \\
\hline Food products, beverages and tobacco & 26.3 & 2 & 20.6 & 14 \\
\hline Motor Vehicles, Trailers and Semitrailers & 35.1 & 3 & 28.4 & 4 \\
\hline Chemicals & 35.4 & 4 & 35.3 & 2 \\
\hline Basic Metals & 37.4 & 5 & 30.2 & 3 \\
\hline \multicolumn{5}{|l|}{ Middle vertical integration } \\
\hline Rubber and Plastics Products & 44.2 & 6 & 25.7 & 7 \\
\hline Electrical machinery \& Apparatus, nec & 45.4 & 7 & 24.9 & 8 \\
\hline $\begin{array}{l}\text { Office and computing machinery - Communication } \\
\text { equipment - Medical, precision and optical instru- } \\
\text { ments }\end{array}$ & 46.9 & 8 & 27.6 & 5 \\
\hline Other non-metallic mineral products & 48.5 & 9 & 26.3 & 6 \\
\hline Machinery and equipment, nec & 49.4 & 10 & 23.4 & 10 \\
\hline Other transport equipment & 49.6 & 11 & 21.2 & 13 \\
\hline Wood, products of wood and cork & 50.2 & 12 & 18.2 & 16 \\
\hline \multicolumn{5}{|l|}{ High vertical integration } \\
\hline Manufacturing, nec; Recycling & 52.2 & 13 & 19.4 & 15 \\
\hline Construction & 52.4 & 14 & 21.4 & 11 \\
\hline Pulp, paper, paper products, printing and Publishing & 53.2 & 15 & 24.9 & 9 \\
\hline Fabricated metal products & 54.2 & 16 & 21.3 & 12 \\
\hline Textiles, textile products, leather and footwear & 64.6 & 17 & 17.8 & 17 \\
\hline
\end{tabular}

along with a high integration of services in the basic metal subsystem, revealing a process of great restructuring.

In searching for traces of "system" outsourcing, interesting results emerge also in terms of cross-country structural comparisons and of structural change. As for the former, Table 3 shows some interesting country peculiarities ${ }^{22}$

Business services have a relatively lower integration in manufacturing in all the transition economies considered, namely Czech Republic, Poland and Hungary. Hungary, in particular, although the country in which in the 1990s there was the largest increase in the service share, both in terms of value added and labour, and where manufacturing labour productivity grew faster (see, for instance, Landesmann, 2000), reveals the least integrated business services in manufacturing: thus suggesting that the increase in the service sector was mainly due to final services, whereas producer services still lag behind. At the opposite extreme, the highest integration of business services in manufacturing is shown

\footnotetext{
${ }^{22}$ Also in this case, the analysis has been accomplished both with respect to total and domestic flows input-output tables. The relative country ranking is quite similar (the Spearman correlation index is 0.83 ).
} 
Table 3: Business services integration in the manufacturing subsystem - middle '90s - Weight of business services on the manufacturing subsystem in terms of hours worked

\begin{tabular}{lcccc}
\multirow{2}{*}{ Country } & \multicolumn{4}{c}{ Business services integration } \\
\cline { 2 - 5 } United Kingdom & 29.1 & 1 & 26.6 & Rank \\
Netherlands & 29.0 & 2 & 25.9 & 2 \\
France & 28.9 & 3 & 26.4 & 4 \\
Australia & 26.9 & 4 & 24.2 & 3 \\
United States & 25.7 & 5 & 27.2 & 6 \\
Canada & 25.4 & 6 & 24.9 & 1 \\
Norway & 25.1 & 7 & 21.4 & 5 \\
Spain & 24.9 & 8 & 21.0 & 8 \\
Korea & 24.2 & 9 & 21.1 & 11 \\
Finland & 23.5 & 10 & 19.0 & 10 \\
Italy & 23.3 & 11 & 18.6 & 14 \\
Japan & 22.9 & 12 & 21.4 & 9 \\
Germany & 22.5 & 13 & 19.7 & 12 \\
Czech Republic & 21.8 & 14 & 19.4 & 13 \\
Poland & 21.4 & 15 & 17.4 & 16 \\
Denmark & 20.3 & 16 & 22.1 & 7 \\
Greece & 19.1 & 17 & 14.9 & 17 \\
Hungary & 15.2 & 18 & 16.1 & 17 \\
\hline Source: our calculation & on OECD & I-O Database & and & $60-$ Industries GGDC Database
\end{tabular}

by the UK, which underwent in the 1980s a deep process of economic restructuring (see, for instance, Matthews and Gardiner, 2000). While the high positions of Australia, the United States and Canada are also confirmed by other studies (e.g. Domberger, 1998) ${ }^{23}$

Coming to the structural change implications, a first set of indications comes from the analysis of the levels and patterns of change in the average degree of both vertical integration and business services integration in manufacturing subsystems.

At the outset, vertical disintegration at the subsystem level appears a quite recent result in OECD manufacturing, of the middle ' $80 \mathrm{~s}$, and indeed a switch with respect to the early ' $80 \mathrm{~s}$. Apart from transport equipment, all the 14 retained manufacturing sectors increased, rather than decreased, their average vertical integration at the beginning of the '80s (Figure 2). At that stage only motor vehicles and other transport sectors in OECD6 seemed to have started undergoing a process of vertical reorganization of labour, being it due to technological change or other causes, such as outsourcing. Moreover, unlike vertical disintegration, the increase of the labour weight of services on manufacturing subsystems was already occurring in the early '80s (Figure 3 ) ${ }^{24}$ Combining the

\footnotetext{
${ }^{23}$ In passing, it is worthwhile observing that the country ranking we got in terms of business services subsystem integration is substantially different from that obtained working with value added and employment shares of business services in total economy. This suggests that "simple" sectoral indicators of tertiarization could be misleading in interpreting more complex cases of structural change (Montresor and Vittucci Marzetti 2006).

${ }^{24}$ It should be noted that, keeping technical coefficients and production organization con-
} 


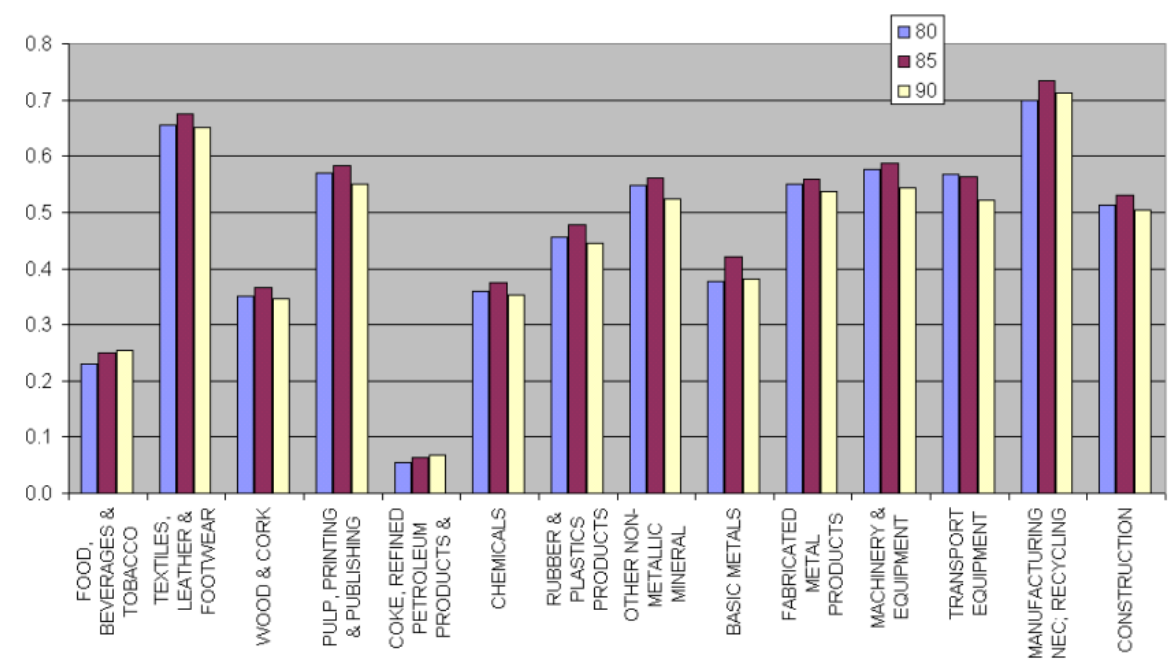

Figure 2: Vertical integration degree of OECD6 manufacturing - cross-country average values: 1980-1990 - Weight of sectors on the relative subsystems (hours worked) - total flows at constant prices

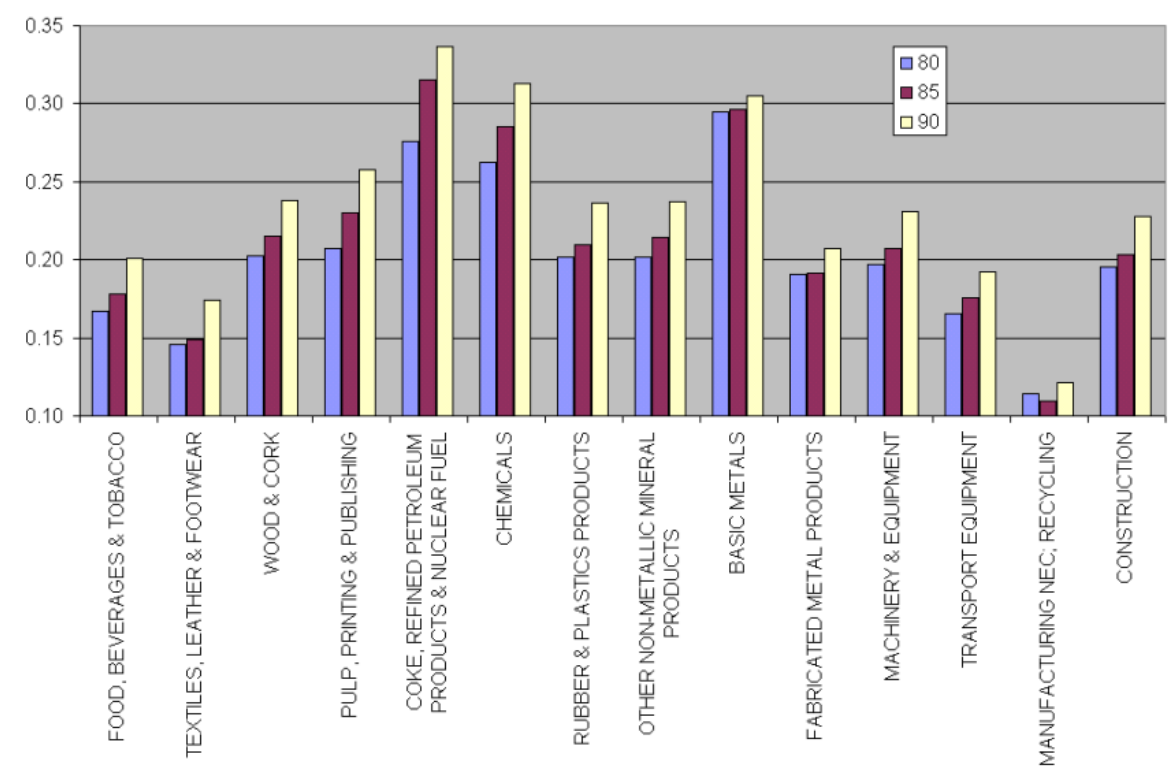

Figure 3: Business services integration in manufacturing subsystems in the OECD6 - cross-country average values: 1980-1990 - Weight of business services in manufacturing subsystems (hours worked) - total flows at constant prices 


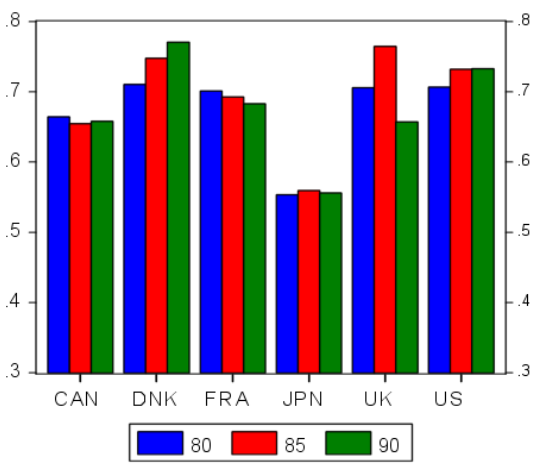

(a) Vertical integration degree

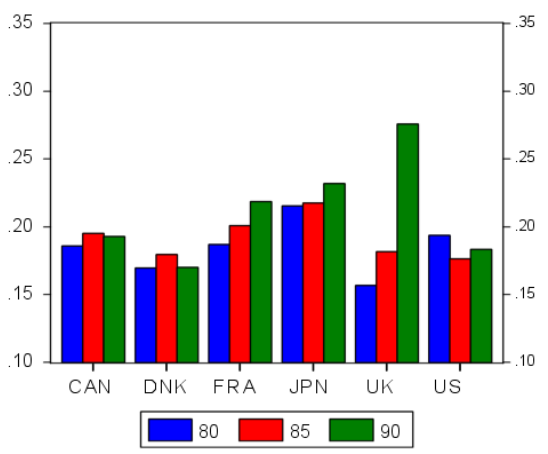

(b) Weight of business services

Figure 4: Total manufacturing: 1980-1990

two results, it seems that, although increasingly more important for manufacturing, in the early ' 80 s business services did not enter in it as substitute yet. This has possibly occurred instead in the middle ' $80 \mathrm{~s}$, as the vertical integration of business services in manufacturing further increased on average and was accompanied, as we saw, by the vertical disintegration of the latter.

Interesting results also emerge by analyzing the changes intervened in the individual countries.

By referring to the whole manufacturing (Figure 4), for example, one can contrast UK with the US. Indeed, while the former reveals a remarkable increase of the business services integration in manufacturing, the latter is the only country in which the weight of services in manufacturing during the ' 80 s, rather than increasing, decreased to an appreciable extent (-5.3\%), thus hinting at a possible different strategy of US manufacturing firms, which got more vertically integrated.

As interesting are the peculiar patterns of change at the level of individual subsystem. The analysis of transport equipment (Figure 5), for example, reveals a notable disintegration in Japan over the whole period and far beyond the others ${ }^{25}$ thus confirming the outcomes of other studies at the firm level on the restructuring of the Japanese sector (see, for instance, Womack et al., 1990).

stant, the weight of business services on manufacturing subsystems tends to growth over time when, as it is generally assumed, the rate of growth of labour productivity in manufacturing is greater than in services. Accordingly, service outsourcing only accelerates the pace of this "natural" tendency.

${ }^{25}$ In 1990 the vertical integration degree of the Japanese transport equipment sector was just 0.34, while in the United States it was nearly twice as much (0.65). Moreover, from the early to the late ' 80 s the rate of change of the vertical integration degree of this sector was $-29.4 \%$, while in the US it was positive and equal to $5.5 \%$. The main findings get confirmed when the vertical integration degree is calculated with respect to domestic, rather than total, production flows. 


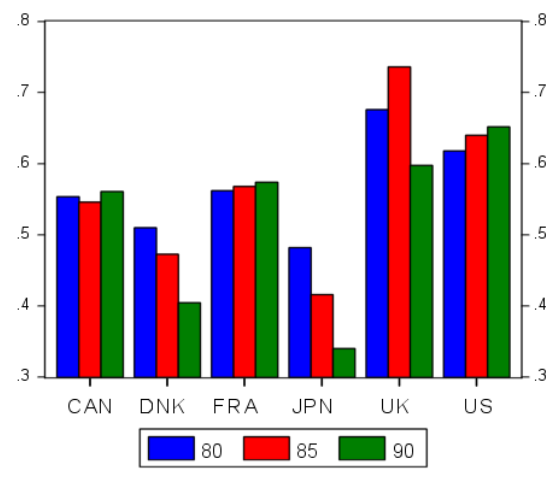

(a) Vertical integration degree

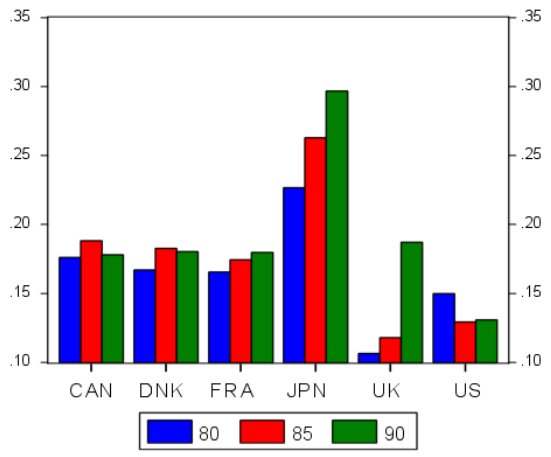

(b) Weight of business services

Figure 5: Transport equipment: 1980-1990

\subsection{Sectoral value added-gross production ratios: are they reliable?}

As we have argued in Section 4.3, although built up by using simple sectoral data, the value added-gross production ratio should be regarded as an outsourcing measurement which refers to the subsystem level. Accordingly, we should expect a certain correlation between such a measurement and that applied in the previous section.

In order to verify this expectation, we calculated the average sectoral value added-gross production ratios over the '90s across the same sectors and countries (OECD18) of the previous sections, worked out the relative cross-country averages and ranked the sectors accordingly (Table 4) (see Appendix B for the dataset description).

Such an operation has been done after having checked for an eventual bias in the $V A / Q$ ratio due to the sectoral proximity to raw materials. As the bias did not turn out evident ${ }^{26}$ we have then analysed the relation between the average sectoral $V A / Q$ ratios and the percentage labour share of the sectors in the relative subsystems (Figure 6).

Quite interestingly, their correlation turns out to be as high as 0.862 and the two rankings are quite similar, except for some sectors, in particular: textiles, leather and footwear; other non-metallic mineral products; and construction (Figure 6).

These and other outliers deserve a special attention, as they actually reveal the different "disintegration" rational the two measures are able to capture. First of all, as we said in Section 4.5, while the vertical integration degree does not change because of phenomena of intrasectoral disintegration, the same does not hold true with respect to the sectoral $V A / Q$ ratio, which tends to decrease when establishments belonging to a certain sector outsource to establishments

\footnotetext{
${ }^{26}$ E.g., basic metals has got a ratio equal to 0.261 , while the ratios of fabricated metals product and electrical \& optical instruments sectors are equal to, respectively, 0.401 and 0.353. The coke, refined petroleum products and nuclear fuel sector has the lowest $V A / Q$ ratio (0.202), though it is certainly one of the most structurally "closer" to raw materials among the manufacturing sectors.
} 
Table 4: Average sectoral $V A / Q$ ratios of OECD18 manufacturing sectors over the '90s - cross-country average values

\begin{tabular}{lc|c}
\hline Industrial sectors & Avg $V A / Q^{a}$ & $\begin{array}{c}\text { Vertical } \\
\text { integration }\end{array}$ \\
\hline Coke, refined petroleum products and nuclear fuel & 0.202 & 9.9 \\
Basic Metals & 0.261 & 37.4 \\
Food products, beverages and tobacco & 0.264 & 26.3 \\
Motor Vehicles, Trailers and Semitrailers & 0.268 & 35.1 \\
Chemicals & 0.332 & 35.4 \\
& & \\
Wood and products of wood and cork & 0.349 & 50.2 \\
Electrical and Optical instruments & 0.353 & 46.4 \\
Textiles, textile products, leather and footwear & 0.361 & 64.6 \\
Other transport equipment & 0.363 & 49.6 \\
Rubber and Plastics Products & 0.368 & 44.2 \\
Machinery and equipment, nec & 0.376 & 49.4 \\
Pulp, paper, paper products, printing and Publishing & 0.380 & 53.2 \\
Manufacturing, nec; Recycling & & 58.5 \\
Fabricated metal products & 0.400 & 52.4 \\
Other non-metallic mineral products & 0.401 & 52.2 \\
\hline Construction & 0.405 & 54.2 \\
\hline
\end{tabular}

Source: our calculation on OECD I-O Database and 60-Industries GGDC Database

${ }^{a}$ Average sectoral value added-gross production ratios 1990-2000

${ }^{b}$ Weight of sectors in the relative subsystems in terms of hours worked - Total flows

classified in the same sector. Apparently, this is what happened during the 1990 s in the textile sector, where phenomena of "intrasectoral outsourcing" were highly frequent. Although to a lesser extent, the same holds true also for wood, wood products and cork; basic metals; and paper products, printing and publishing. Quite interestingly, what emerge from the data can be related to the recent technical changes occurred in these sectors, especially in the last two, involving a reduction in their minimum efficient scale. We refer in particular to the emergence of mini-mills in the steel production (e.g. Audretsch and Feldman. 1996) and to the massive computerization occurred in printing and publishing in the last years (e.g. Domberger, 1998).

A different argument holds with respect to constructions, other non metallic mineral products and rubber and plastics products, which appear less disintegrated in terms of $V A / Q$ than what would be in terms of the relative sectorsubsystem ratio. As we pointed out in Section 4.5. this could be due to the peculiar market structure of these sectors, of the first in particular, in which monopolistic rents are quite diffuse and hinder the outsourcing revealing power of the $V A / Q$ ratio.

Although both the kinds of interpretations need to be confirmed with other data, suffice here to notice how the two indicators of disintegration/integration should be used in a complementary way to have a better understanding of the investigated phenomenon. 


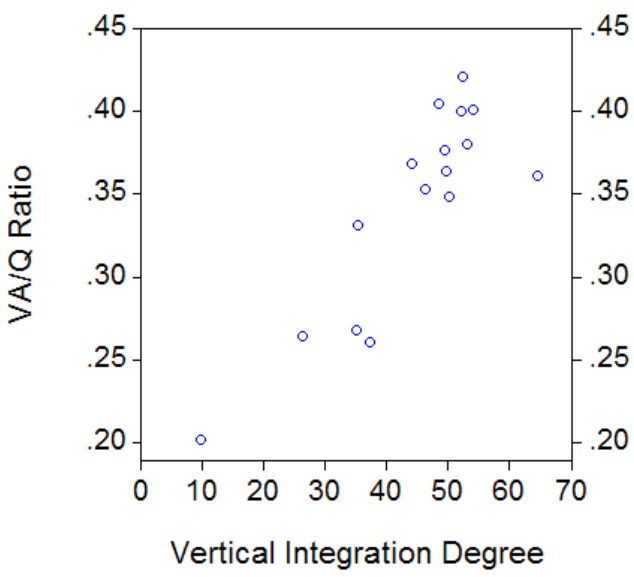

Figure 6: Sectoral $V A / Q$ ratios vs vertical integration degrees

\subsection{Service outsourcing: what input-output technical co- efficients have to say?}

The final point to address is how consistent the previous indicators of "system" integration of business services into the production of manufactured goods are with the more "direct" sector-based indicators of outsourcing we have presented in Section 4, that is $S E R V / Q$ and $S E R V / L A B R$.

At the outset, let us observe that, once calculated for the OECD18 in the middle '90s, the rank correlation index between $S E R V / Q$ and $S E R V / L A B R$ is very low (0.31). And also the relative ranking shows how $S E R V / L A B R$ does not turn out very reliable in cross-country comparisons, as possibly affected quite a lot by the relative cost of labour (Table 5).

Second, the ranking made according to $S E R V / Q$ is not consistent with the results we have previously obtained at the subsystem level (see Table 3) ${ }^{27}$ thus suggesting how these sectoral indicators should be retained measures of changes in service outsourcing practices at the sectoral level over time, with differences and some degree of complementarity with respect to the ones analysed at the subsystem level. The replication of the analysis carried out in Section 5.1 for manufacturing as a whole and for transport equipment can be of some help in illustrating this point (Figures 7 and 8 ).

Quite interestingly, as far as the European countries are concerned, the two data series are quite consistent between them and decisively supportive of the outsourcing hypothesis. Indeed, these countries show significant increases in both the variables over the whole period. In particular, the data provide further evidence on the economic restructuring of the UK manufacturing during the '80s, and especially in the last five years ${ }^{28}$ However, it has to be noted that the

\footnotetext{
${ }^{27}$ The correlation indexes, both linear and rank, between $S E R V / Q$ in manufacturing and the business services integration in manufacturing subsystem are definitively quite low. The linear correlation is 0.42 , while the rank one is even lower and equal to 0.325 . As for $S E R V / L A B R$, its rank correlation with the indicator at the subsystem level is as low as 0.063 , while the correspondent linear correlation is nearly null (-0.013).

${ }^{28}$ For manufacturing as a whole, for example, $S E R V / Q$ increased more than $66 \%$, while $S E R V / L A B R$ of $60.6 \%$.
} 
Table 5: Business services expenditure per production unit $(S E R V / Q)$ and on labour compensation $(S E R V / L A B R)$ in manufacturing in middle $90 \mathrm{~s}$

\begin{tabular}{lcccc}
\hline Country & $S E R V / Q$ & Rank & SERV/LABR & Rank \\
\hline United Kingdom & 0.186 & 1 & 0.752 & 9 \\
France & 0.183 & 2 & 0.855 & 4 \\
Denmark & 0.183 & 3 & 0.721 & 15 \\
Norway & 0.178 & 4 & 0.829 & 6 \\
Germany & 0.177 & 5 & 0.624 & 17 \\
Japan & 0.177 & 6 & 0.775 & 8 \\
Australia & 0.176 & 7 & 0.986 & 2 \\
Poland & 0.171 & 8 & 1.128 & 1 \\
United States & 0.168 & 9 & 0.752 & 10 \\
Italy & 0.158 & 10 & 0.840 & 5 \\
Netherlands & 0.152 & 11 & 0.751 & 11 \\
Spain & 0.152 & 12 & 0.750 & 12 \\
Czech Republic & 0.139 & 13 & 0.986 & 3 \\
Finland & 0.128 & 14 & 0.667 & 7 \\
Greece & 0.127 & 15 & 0.788 & 18 \\
Canada & 0.121 & 16 & 0.593 & 13 \\
Hungary & 0.115 & 17 & 0.737 & 14 \\
Korea & 0.111 & 18 & 0.728 & Databs \\
\hline
\end{tabular}

Source: our calculation on OECD I-O Database and 60-Industries GGDC Database

integration of business services in UK manufacturing is largely underestimated by the two indicators of the present section, both in terms of levels and of rates of changes, as it clearly emerges comparing Figures 4, 5 with Figures 7, 8, This suggests how considering both direct and indirect intersectoral relationships matters in dealing with outsourcing as much as with other processes of economic restructuring.

Apart from Canada and US, where data do not show significant tendencies towards service outsourcing ${ }^{29}$ (the only exception is represented by the US transport equipment sector in the late '80s) a special attention should be paid to the case of Japan, and of the Japanese transport equipment sector in particular, for which the data seem to be somehow inconsistent. Indeed, as we saw in Section 5.1, during the '80s the growth rate of business services integration in the transport equipment subsystem was of $30.8 \%$, and accompanied by a related process of sectoral disintegration $(-29.4 \%)$, thus clearly signalling an intense process of economic restructuring within the subsystem. This fact gets somehow confirmed by the data on $S E R V / L A B R$ : for transport equipments, the overall growth rate of the indicator for the ' 80 s was nearly $25 \%$, although this increase mainly occurred in the last five years 30

\footnotetext{
${ }^{29}$ In the United States during the ' 80 s the overall rate of change of $S E R V / Q$ for the whole manufacturing is negative and equal to $-5.2 \%$, whereas the rate of change of $S E R V / L A B R$, though positive, is relatively small $(6.9 \%)$.

${ }^{30}$ At the same time, the indicator increased a lot also for machinery \& equipment $(+35.4 \%)$, the main supplier sector of transport equipment. As for basic metals and fabricated metals products, the other two manufacturing sectors with relevant labour share in the transport equipment subsystem, the rates of change of $S E R V / L A B R$ were, respectively, $24.1 \%$ and $-2.9 \%$. Furthermore, looking at the average levels of the indicators in the two sectors, Japan
} 


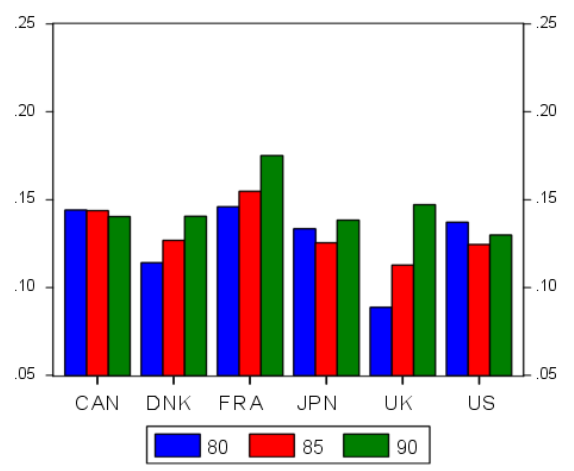

(a) Total Manufacturing

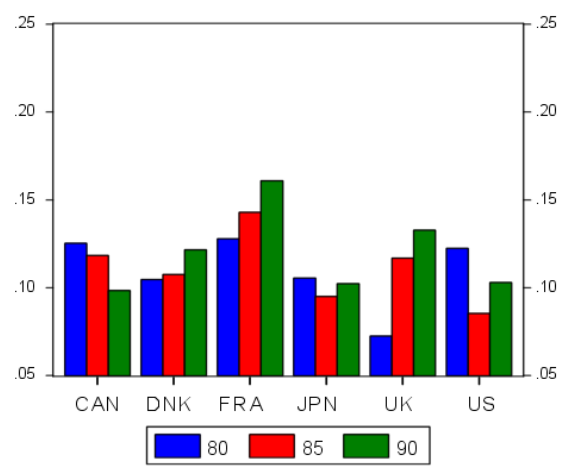

(b) Transport Equipment

Figure 7: Intermediate business services expenditure per production unit (constant prices): 1980-1990

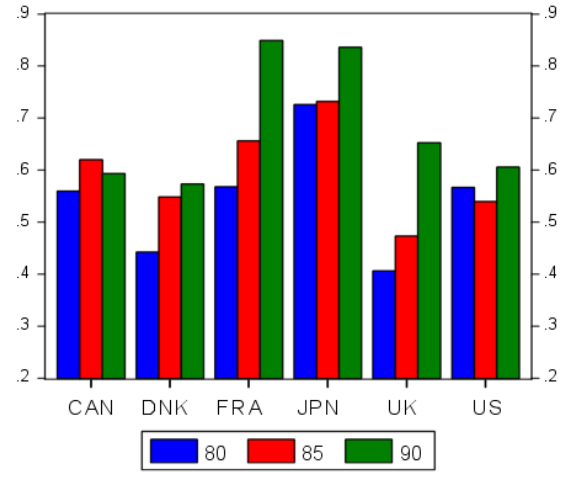

(a) Total Manufacturing

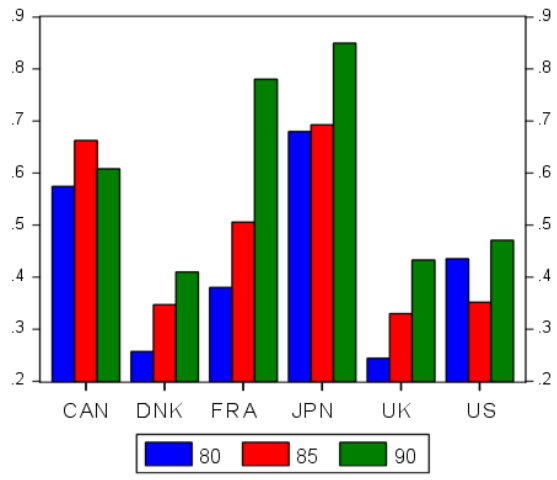

(b) Transport Equipment

Figure 8: Intermediate business services expenditure on labour compensation (current prices): 1980-1990

However, the same pattern is not revealed by the data on $S E R V / Q$. Indeed, unlike for the other countries, in the Japanese sector there was no significant increase in business services expenditure per production unit during the 1980s (see Figure 7(b) , and the same does hold true also for its traditional supplier sectors, that is, machinery \& equipment, basic metals, rubber and plastics products and other fabricated metal products ${ }^{31}$ In synthesis, it seems that the

shows the highest values.

${ }^{31}$ Although sectoral input flows at constant prices from business services increased more than $89.8 \%$, the overall increase in sectoral gross production was $95.6 \%$, thus determining a reduction in the coefficients of $-2.94 \%$. Looking at the Japanese data on $S E R V / Q$ for machinery \& equipment; basic metals; rubber and plastics products; and other fabricated metal products, the overall rates of change for the $1980 \mathrm{~s}$ were, respectively, $-11.5 \%, 9.9 \%$, $-16.6 \%,-2.6 \%$. (With respect to the same period, in the UK the rates of change in the corresponding sectors were $40.9 \%,-23.1 \%, 70.9 \%$ and $43.6 \%$.) In addition, examining the average level of $S E R V / Q$ over the '80s, rather than its change rates, it turns out that it is 


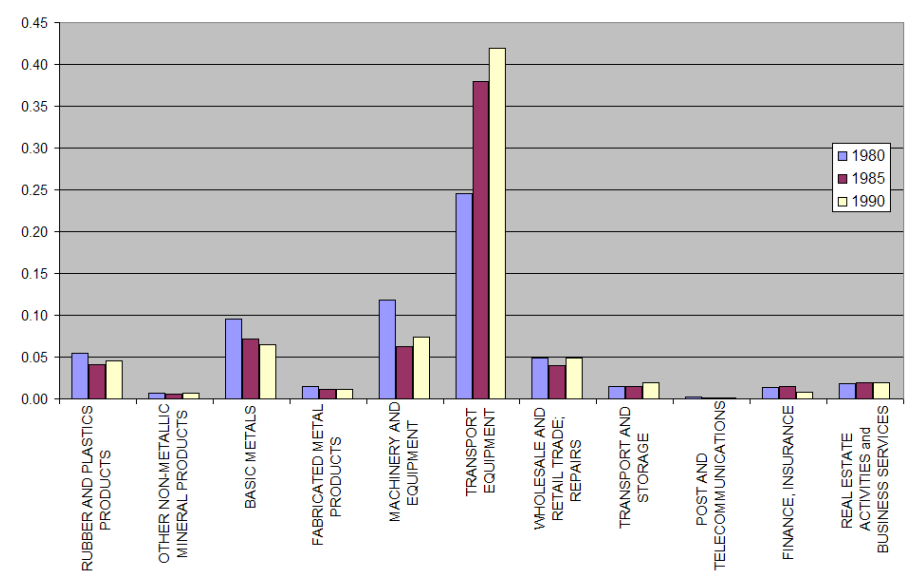

(a) Japan

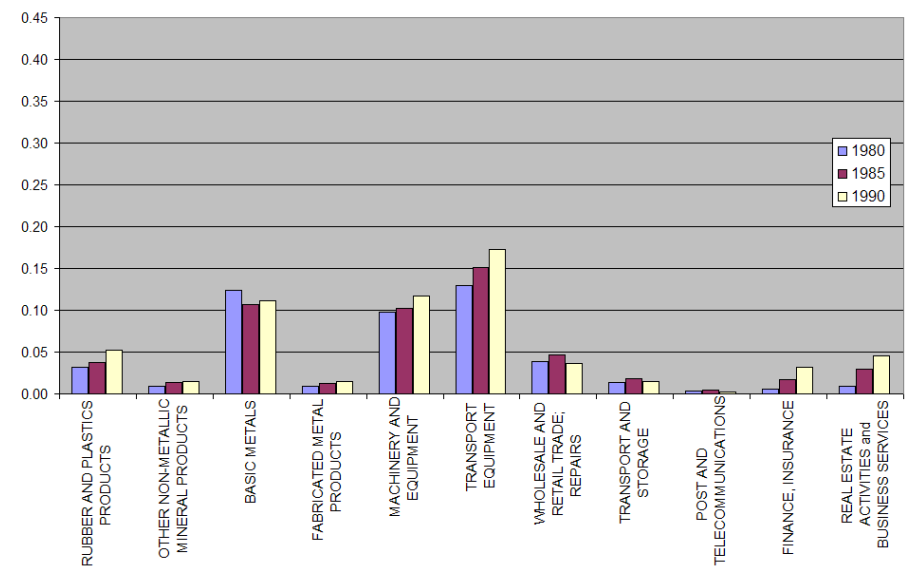

(b) United Kingdom

Figure 9: Technical coefficients in transport equipment (constant prices)

Japanese economic restructuring, while reflected in the changes occurred in the employment structure, does not result from the data on intermediate service consumptions per production unit.

A tentative explanation of this apparent inconsistency can be found by recalling the relationship between intrasectoral outsourcing and sectoral inputoutput coefficients we have pointed out in Section 4.2 In such a case, as we said, $S E R V / Q$ would tend to decrease in the outsourcing sector $i$, whereas, ceteris paribus, neither its $S E R V / L A B R$ nor the indicators at the subsystem level would be affected. What is more, all the technical coefficients of the same sector $\left(a_{i j}\right)$ would tend to decrease, with the exception of the autocoefficients $\left(a_{i i}\right)$, which, on the contrary, would increase.

In order to ascertain whether this was the case for the Japanese transport equipment sector, we have compared levels and changes of its technical coefficients with the ones experienced by the same sector in the other countries of particularly small for transport equipment in Japan. 
our dataset. The results seem to support our interpretation. Indeed, over the ' 80 s the autocoefficients of the transport equipment sector in Japan increased by $70.9 \%$, while, among the remaining five countries of the OECD6 set, the largest increase occurred in the UK and it was of just 32.9\% ${ }^{32}$ (Figure 9 shows the technical coefficients of the sector in Japan and UK over the 1980s.) At the same time, in the Japanese transport equipment sector, all the remaining technical coefficients decreased. Among these, we have to notice the changes occurred in the coefficients referred to basic metals, machinery \& equipment and fabricated metal products, three of the most important and complementary inputs in the production of transport equipment 33

Evidences of a certain intrasectoral disintegration of the Japanese transport equipment sector are therefore apparent. This interpretation is consistent with the data on employees per establishment in the automobile industry. Indeed, in the late 1980s Japan had the lowest number of employees per establishment among the top five economies in the World at that time (Williams et al., 1998 p.25). However, other factors might have played a role in explaining the inconsistency we have detected. First of all, the particular features of the Japanese manufacturing, and of transport equipment in particular, sometimes pointed out in empirical studies (e.g. Domberger, 1998), might have led to underestimate the service inputs of manufacturing sectors. Indeed, given the particular organizational relationships of the Japanese industrial structure (of which "keiretsu" are the most notable example), input prices might be more similar to intra-firm "transfer prices" rather than normally negotiated "market prices" (see, for instance, Jarillo, 1993). Second, the large labour productivity gains reached in the transport equipment during the ' 80 s in Japan, not accompanied by an equal increase of labour productivity in the service sectors, might have caused an increase in the service labour share of the transport equipment subsystem. Thus, the observed changes in the sectoral labour shares might have been also due to the different growth rates of sectoral productivity. However, although more than plausible, all these interpretations turn out to be complementary, rather than primary, with respect to the particular disintegration hypothesis we have put forward.

\section{Conclusive remarks}

Although mainly investigated as a process of organizational change, in particular of the firm boundaries, outsourcing has important implications also for the structure of the economic system in which the "outsourcee" and the "outsourcer" firms operate. The organizational and structural changes outsourcing determines are thus nothing but two coins of the same medal.

\footnotetext{
${ }^{32}$ It is worth noting that the increase of $a_{i i}$ we have registered in Japan is not due to changes in the composition of the sector. Also by increasing the level of disaggregation, the basic insights get confirmed. Indeed, the growth rate of motor vehicles, trailers and semitrailer in Japan was of $52.7 \%$, whereas in the UK it was of just $12.9 \%$.

${ }^{33}$ Over the ' $80 \mathrm{~s}$, in all the countries but Japan the reduction in the coefficients of basic metals was accompanied by an increase for machinery \& equipment and fabricated metal products. On the contrary, in Japan they all decreased: $-31.4 \%$ for basic metals, $-37.3 \%$ for machinery \& equipment and $-22.7 \%$ for fabricated metal products. One might argue that these results, rather than by disintegration, are mainly due to technical progress. However, if it was so, how to explain the marked increase of the autocoefficients? Technical change might not be the only explanation.
} 
In bridging the micro and the macro-analysis of outsourcing - an effort so far successful only in international trade studies (for a survey see Spencer, 2005) - this paper illustrates, compares and applies a "battery" of an input-output kind of outsourcing indicators. That is, indicators which help in disentangling to which extent and in which way the different externalisation decisions of the firms turn into changes of the intersectoral and intrasectoral relationships of the economic system in which they operate. In other words, a set of indicators through which outsourcing, especially of producer services, can be accounted for in explaining structural change along with other more "popular" determinants of it, such as technical, production and demand-led changes.

Given that the different structural change determinants of one economy are at work simultaneously, an accurate analysis and interpretation of the indicators we discuss should be accompanied by a suitable decomposition of their relative weight. Indeed, some decomposition techniques have been recently put forward for this scope (e.g. Dietrich, 1999, McCarthy and Anagnostou, 2004). However, their construction and interpretation appears to us still problematic and requires further research effort. Accordingly, we decided to place this issue on our future research agenda. In this paper we have instead opted to: on the one hand, discuss the rational of the same indicators, on the other hand, to carry out their empirical application just by alerting about the need of controlling for extra-outsourcing determinants when necessary.

The discussion of the rational of the outsourcing indicators we present leads us to a first important result. Although they are all affected by the externalisation decisions of the correspondent firms, and thus inform about it, their interpretative power differs: either because they retain total (at the subsystem level) rather than direct (at the sectoral level) outsourcing effects, or because they are able rather than unable to distinguish inter-sectoral from intra-sectoral outsourcing, or because they are affected rather than unaffected by the market structure of the relevant sector, just to mention a few differentiating mechanisms. Accordingly, the indicators of outsourcing of the paper should be used as complementary rather than as substitute among them, while looking for the "best", or the "most revealing" one could be misleading.

The illustrative empirical application we carried out with respect to a set of OECD countries over the ' 80 s and the middle '90s corroborates this suggestion. Some results confirm, on a comparable and systematic basis, what previous work had already suggested on the basis of case-studies and/or nation specific analyses, such as, for example, the idiosyncratic resort to service outsourcing, both in terms of levels and of growth rates, of the UK manufacturing sectors. Some of the results we got are instead quite original, as they have been obtained by working on a new OECD dataset, covering updated input-output tables for a larger set of countries than the "old" one, and by crossing it with other newly available sources of sectoral data (e.g., the 60-Industry Database of the Groningen Growth and Development Centre). The evidence we obtained for the former socialist European countries, usually retained to have been invested by a massive tertiarization process over the 1990s, but here characterized by the lowest degree of integration of business services in manufacturing subsystems, is one of the most relevant of these results. Finally, some of the outcomes that we got turn out to be inconsistent or mixed-up, as different indicators point to, at least apparently, different predictions in terms of outsourcing: the case of the Japanese transport equipment sector is for sure the most representative of them. 
On the other hand, an accurate complementary use of the different outsourcing indicators we have discussed turns out to be helpful in solving these apparent contradictions and in eliminating the inherent biases by which some of them are affected. In the Japanese case, for example, a closer look at the technical inputoutput coefficients of transport equipment sheds some light on the hypothesis of an intrasectoral, rather than intersectoral, disintegration process over the ' $80 \mathrm{~s}$ and the middle '90s.

In closing the paper, it seems to us that, although in the need of controlling for other factors, the indicators we have presented could be used as complementary (and possibly rough) proxies of a structural change determinant which should be extrapolated from the "black-box" of other important economic processes.

\section{Appendix A Intrasectoral outsourcing and i-o indicators. A formal treatment}

As argued in Section 4.2, intrasectoral outsourcing in a certain sector $j$ entails a change of the intrasectoral flows $\left(w_{j j}\right)$ by a certain amount $\left(d_{j}\right)$ and a correspondent change in the sectoral gross production $\left(Q_{j}\right)$ by the same amount.

Denoting with $\hat{\mathbf{d}}$ the diagonalized vector of the sectoral changes $d_{j}$, the matrix of input-output technical coefficients (A), formally defined in Equation (1), therefore changes as follows:

$$
\mathbf{A}_{d}=(\mathbf{W}+\hat{\mathbf{d}})(\hat{\mathbf{q}}+\hat{\mathbf{d}})^{-1}=\left(\begin{array}{ccc}
\frac{w_{11}+d_{1}}{Q_{1}+d_{1}} & \cdots & \frac{w_{1 n}}{Q_{n}+d_{n}} \\
\vdots & \ddots & \vdots \\
\frac{w_{n 1}}{Q_{1}+d_{1}} & \ldots & \frac{w_{n n}+d_{n}}{Q_{n}+d_{n}}
\end{array}\right)
$$

Given that $0 \leq w_{i j}<Q_{j}$, it follows that:

$$
\frac{w_{j j}+d_{j}}{Q_{j}+d_{j}} \begin{cases}>\frac{w_{j j}}{Q_{j}} & \text { if } d_{j}>0 \\ <\frac{w_{j j}}{Q_{j}} & \text { if } d_{j}<0\end{cases}
$$

and

$$
\frac{w_{i j}}{Q_{j}+d_{j}}\left\{\begin{array}{cl}
<\frac{w_{i j}}{Q_{j}} & \text { if } d_{j}>0 \\
>\frac{w_{i j}}{Q_{j}} & \text { if } d_{j}<0
\end{array}\right.
$$

Thus, an increase (decrease) in the value of the duplication in sector $j$, because of an increased (decreased) intrasectoral disintegration within the sector, $d_{j}>0\left(d_{j}<0\right)$, will cause, ceteris paribus, an increase (decrease) of the relevant autocoefficient $\left(a_{j j}\right)$ and a decrease (increase) in all the remaining coefficients $\left(a_{i j}\right.$ with $\left.i \neq j\right)$.

Moreover, given that the value added is not affected by duplication and intrasectoral outsourcing does not entail any reorganization of production among sectors, the sectoral value added remains unchanged. Thus, we have that:

$$
\frac{V A_{j}}{Q_{j}+d_{j}} \begin{cases}<\frac{V A_{j}}{Q_{j}} & \text { if } d_{j}>0 \\ >\frac{V A_{j}}{Q_{j}} & \text { if } d_{j}<0\end{cases}
$$


Hence, ceteris paribus, the sectoral value added/gross production ratio tends to decrease for phenomena of intrasectoral outsourcing.

Let us also note that, given a non-service sector $i$, if its intrasectoral disintegration increases, this will cause, ceteris paribus, a reduction in $S E R V_{i} / Q_{i}$, $S E R V_{i} / L A B R_{i}$, defined in Section 4.1, will not change.

Finally, it remains to prove that intrasectoral outsourcing cannot alter any of the indicators at the subsystem level discussed in Section 4.4, namely vertical integration degree and business services integration. In order to do so, let us prove the following equality:

$$
\hat{\mathbf{q}}^{-1}\left(\mathbf{I}-\mathbf{W} \hat{\mathbf{q}}^{-1}\right)^{-1}=(\hat{\mathbf{q}}+\hat{\mathbf{d}})^{-1}\left(\mathbf{I}-(\mathbf{W}+\hat{\mathbf{d}})(\hat{\mathbf{q}}+\hat{\mathbf{d}})^{-1}\right)^{-1}
$$

Inverting both sides of the equality and recalling that $\left(\mathbf{M}_{1} \mathbf{M}_{2}\right)^{-1}=\mathbf{M}_{2}^{-1} \mathbf{M}_{1}^{-1}$, where $\mathbf{M}_{1}$ and $\mathbf{M}_{2}$ are two generic conformable square matrices, we obtain:

$$
\begin{aligned}
\left(\hat{\mathbf{q}}^{-1}\left(\mathbf{I}-\mathbf{W} \hat{\mathbf{q}}^{-1}\right)^{-1}\right)^{-1} & =\left((\hat{\mathbf{q}}+\hat{\mathbf{d}})^{-1}\left(\mathbf{I}-(\mathbf{W}+\hat{\mathbf{d}})(\hat{\mathbf{q}}+\hat{\mathbf{d}})^{-1}\right)^{-1}\right)^{-1} \\
\left(\mathbf{I}-\mathbf{W} \hat{\mathbf{q}}^{-1}\right) \hat{\mathbf{q}} & =\left(\mathbf{I}-(\mathbf{W}+\hat{\mathbf{d}})(\hat{\mathbf{q}}+\hat{\mathbf{d}})^{-1}\right)(\hat{\mathbf{q}}+\hat{\mathbf{d}}) \\
\hat{\mathbf{q}}-\mathbf{W} & =(\hat{\mathbf{q}}+\hat{\mathbf{d}})-(\mathbf{W}+\hat{\mathbf{d}}) \\
0 & =0
\end{aligned}
$$

that demonstrates the previous equality.

From Equation (5) it follows that:

$$
\mathbf{B}=\hat{\mathbf{q}}^{-1}(\mathbf{I}-\mathbf{A})^{-1} \hat{\mathbf{y}}=(\hat{\mathbf{q}}+\hat{\mathbf{d}})^{-1}\left(\mathbf{I}-(\mathbf{W}+\hat{\mathbf{d}})(\hat{\mathbf{q}}+\hat{\mathbf{d}})^{-1}\right)^{-1} \hat{\mathbf{y}}
$$

Thus, intrasectoral disintegration phenomenona do not alter the operator B and the other matrix defined at the subsystem level, C. Accordingly, the indicators based on this matrix are not affected by intrasectoral outsourcing.

\section{Appendix B Dataset description}

Data have been obtained from different datasets. Input-output tables come from both the new input-output dataset, recently built up by the OECD (2005) and the "old" STAN input-output database for the '80s (OECD, 1995).

Sectoral data on total hours worked have been obtained from the 60-Industry Database of the Groningen Growth and Development Centre (GGDC, 2005).

The data on sectoral gross production and value added over the '90s used for calculating the average sectoral ratios in the analyses carried out in Section 4.3 come from the OECD STAN database (OECD, 2004). Because of missing data, in this specific application we have excluded Australia from the average ratio of the construction sector. Furthermore, when for some country some of the needed disaggregated data were missing, we used the least aggregated data available assuming that, for that country, the proportion between the disaggregated data and the more aggregated ones is the same as that between the correspondent average values. This procedure has been applied to the following missing values: Chemicals and chemical products (Cod. 24) and Rubber 
and plastics products (Cod. 25) for Norway, using the data of Chemical, rubber, plastics and fuel products (Cod. 23-25); Basic Metals (27) and Fabricated metal products (28) for Australia and Czech Republic, using the data of Basic metals and fabricated metal products (27-28); Motor vehicles, trailers and semi-trailers (34) and Other transport equipment (35) for Czech Republic, using the data on Transport equipment (34-35). The ensuing results are quite robust and do not change significantly if some other method is adopted, such as, for instance, simply calculating the sectoral averages without the sectors of the countries for which the data are missing.

\section{Appendix C Business sector services}

\begin{tabular}{lc}
\hline Sector & ISIC Rev.3 Codes \\
\hline Wholesale and retail trade; repairs & $50-52$ \\
Hotels and restaurants & 55 \\
Transport and storage & $60-63$ \\
Post and telecommunications & 64 \\
Financial intermediation & $65-67$ \\
Real estate, renting and business activities & $70-74$ \\
\hline
\end{tabular}

\section{Appendix D Country coverage}

\begin{tabular}{|c|c|c|c|c|}
\hline \multirow[t]{2}{*}{ Country } & \multicolumn{4}{|c|}{ Input-Output Tables } \\
\hline & early '80s* & mid-'80s* & early '90s* & mid-'90s \\
\hline Australia & & & & 1995 \\
\hline Canada & 1981 & 1986 & 1990 & 1997 \\
\hline Czech Republic & & & & 1995 \\
\hline Denmark & 1980 & 1985 & 1990 & 1997 \\
\hline Finland & & & & 1995 \\
\hline France & 1980 & 1985 & 1990 & 1995 \\
\hline Germany & & & & 1995 \\
\hline Greece & & & & 1994 \\
\hline Hungary & & & & 1998 \\
\hline Italy & & & & 1992 \\
\hline Japan & 1980 & 1985 & 1990 & 1995 \\
\hline Korea & & & & 1995 \\
\hline Netherlands & & & & 1995 \\
\hline Norway & & & & 1997 \\
\hline Poland & & & & 1995 \\
\hline Spain & & & & 1995 \\
\hline United Kingdom & 1979 & 1984 & 1990 & 1998 \\
\hline United States & 1982 & 1985 & 1990 & 1997 \\
\hline
\end{tabular}




\section{Appendix E Sector classification}

\begin{tabular}{lc}
\hline Sector & ISIC Rev.3 Codes \\
\hline Food products, beverages and tobacco & $15-16$ \\
Textiles, textile products, leather and footwear & $17-19$ \\
Wood and products of wood and cork & 20 \\
Pulp, paper, paper products, printing and publishing & $21-22$ \\
Coke, refined petroleum products and nuclear fuel & 23 \\
Chemicals (including pharmaceuticals) & 24 \\
Rubber and plastics Products & 25 \\
Other non-metallic mineral products & 26 \\
Basic metals & 27 \\
Fabricated metal products (except machinery and equipment) & 28 \\
Machinery \& equipment & 29 \\
...Machinery and equipment, nec & $30,32-33$ \\
...Office and computing machinery - communication equipment - medical, \\
precision and optical instruments & 31 \\
...Electrical machinery and apparatus, nec & 31 \\
Transport equipment & $36-37$ \\
...Motor vehicles, trailers and semitrailers & 45 \\
...Other transport equipment & 34 \\
Manufacturing, nec; recycling & 35 \\
Construction & 2 \\
\hline
\end{tabular}

\section{References}

Abraham, K. G., Taylor, S. K., 1996. Firms use of outside contractors: Theory and evidence. Journal of Labor Economics 14 (3), 394-424.

Adelman, M. A., 1955. Concept and statistical measurement of vertical integration. In: Stigler, G. J. (Ed.), Business Concentration and Price Policy. NBER-Priceton University Press, pp. 281-322.

Antonelli, C., 1988. The emergence of the network-firm. In: Antonelli, C. (Ed.), New Information Technology and Industrial Change: the Industrial Case. Kluwer Academic Pubblishers, Dortrecth, pp. 13-22.

Audretsch, D. B., Feldman, M. P., 1996. Innovative clusters and the industry life cycle. Review of Industrial Organization 11, 253-273.

Baranzini, M., Scazzieri, R., 1990. Economic structure: Analytical perspectives. In: Baranzini, M., Scazzieri, R. (Eds.), The Economic Theory of Structure and Change. Cambridge University Press, Cambridge, Ch. IX, pp. 227-333.

Campa, J., Goldberg, G., 1997. The evolving external orientation of manufacturing industries: Evidence from four countries. Federal Reserve Bank of New York Economic Policy Review 4, 79-99.

Diestel, R., 2005. Graph Theory, $3^{\text {th }}$ Edition. Springer-Verlag Heidelberg, New York. 
Dietrich, M., 1999. Explaining economic restructuring: an input-output analysis of organisational change in the European Union. International Review of Applied Economics 13 (2), 219-240.

Domberger, S., 1998. The Contracting Organization. A Strategic Guide to Outsourcing. Oxford University Press, Oxford.

Feenstra, R. C., 1998. Integration of trade and disintegration of production in the global economy. Journal of Economic Perspective 12 (4), 31-50.

Feenstra, R. C., Hanson, G. H., 1999. The impact of outsourcing and hightechnology capital on wages: Estimates for the United States, 1979-1990. Quarterly Journal of Economics August, 907-940.

Gershuny, J., Miles, I. D., 1983. The New Service Economy: The Transformation of Employment in Industrial Societies. Praeger, New York.

GGDC, February 2005. Data sources and methodology of the 60-industry database of the Groningen Growth and Development Centre. http://www . ggdc.net.

Ginzberg, E., Vojta, G., 1981. The service sector of the U.S. economy. Scientific American 3.

Glass, A. J., 2004. Outsourcing under imperfect protection of intellectual property. Review of International Economics 12 (5), 867-884.

Gossling, W., 1972. Productivity Trends in a Sectoral Macro-Economic Model. Input-Output Publishing, London.

Grossman, G., Helpman, E., 2002. Integration versus outsourcing in industry equilibrium. The Quarterly Journal of Economics 117, 85-120.

Gupta, S., Steedman, I., 1971. An input-output study of labour productivity in UK. Oxford Bulletin of Economics and Statistics 33, 21-34.

Hummels, D., Rapoport, D., Yi, K.-M., 1998. Vertical specialization and the changing nature of world trade. Federal Reserve Bank of New York Economic Policy Review 4, 79-99.

Jacobides, M. G., Billinger, S., January 2005. Designing the boundaries of the firm: from "make, buy or ally" to the dynamic benefits of vertical architecture. London Business School - Strategic and International Management Working Paper Series, working Paper.

Jarillo, J., 1993. Strategic Networks: Creating the Borderless Organization. Butterworth-Heinemann, Oxford.

Jones, R., Kierzkowski, H., Lurong, C., 2005. What does evidence tell us about fragmentation and outsourcing? International Review of Economics and Finance $14,305-316$.

Jones, R. W., Kierzkowski, H., 2001. A framework for fragmentation. In: Arndt, S. W., Kierzkowski, H. (Eds.), Fragmentation: New production patterns in the world economy. Oxford University Press, Oxford and New York, pp. 1734 . 
Kohler, W., 2004. Aspects of international fragmentation. Review of International Economics 12 (5), 793-816.

Laffer, A. B., 1969. Vertical integration by corporations, 1929-1965. Review of Economics and Statistics February, 1969, 91-93.

Landesmann, M., 2000. Structural change in the transition economies, 19891999. Economic Survey of Europe 2/3, 95-123.

Matthews, H., Gardiner, V. (Eds.), 2000. The Changing Geography of the United Kingdom. Routledge, New York.

McCarthy, I., Anagnostou, A., 2004. The impact of outsourcing on the transaction costs and boundaries of manufacturing. International Journal of Production Economics 88, 61-71.

McFetridge, D. G., Smith, D. A., 1988. The Economics of Vertical Disintegration. Fraser Institute, Vancouver.

Milberg, W. S., 1991. Structural change and international competitiveness in Canada: an alternative approach. International Review of Applied Economics $5,77-93$.

Momigliano, F., Siniscalco, D., 1982a. The growth of service employment: a reappraisal. BNL Quarterly Review 142, 269-306.

Momigliano, F., Siniscalco, D., 1982b. Note in tema di terziarizzazione e deindustrializzazione. Moneta e Credito 138, 143-181.

Momigliano, F., Siniscalco, D., 1984. Technology and international specialization. BNL Quarterly Review 150, 257-284.

Montresor, S., Mazzanti, M., Pini, P., 2006. The general profile of the outsourcing firm: Empirical evidence for a local production system of Emilia Romagna. mimeo, University of Bologna.

Montresor, S., Vittucci Marzetti, G., 2006. Outsourcing and structural change in the OECD area. mimeo, University of Bologna.

OECD, 1995. The OECD input-output database. sources and methods. http: //www. oecd.org/sti/stan.

OECD, 2004. STAN database. http://www.oecd.org/sti/stan.

OECD, 2005. Input-output tables (2002 edition). http://www.oecd.org/sti/ stan.

Pasinetti, L. L., 1973. The notion of vertical integration in economic analysis. Metroeconomica 1.

Rampa, G., 1982. Commento a Momigliano e Siniscalco. Moneta e Credito 139, $475-479$.

Rampa, G., Rampa, L., 1982. Sul mutamento tecnologico nell'economia italiana, 1959-1975: Un'analisi input-output. Ricerche economiche XXXVI (4), 303341. 
Spencer, B. J., 2005. International outsourcing and incomplete contracts. Working Paper 11418, National Bureau of Economic Research.

Sraffa, P., 1960. Production of Commodities by Means of Commodities. Cambridge University Press, Cambridge.

Stanback, T. M., 1979. Understanding the Service Economy. Johns Hopkins University Press, Baltimora.

Stigler, G. J., June 1951. The division of labor is limited by the extent of the market. The Journal of Political Economy 59 (3), 185-193.

Tucker, I. B., Wilder, R. P., 1977. Trends in vertical integration in the U.S. manufacturing sector. Journal of Industrial Economics 26 (1), 81-94.

Van Long, N., 2005. Outsourcing and technology spillovers. International Review of Economics \& Finance 14 (3), 297-304.

Williams, K., Haslam, C., Williams, K., Johal, S., 1998. Cars: Analysis, History, Cases. Berghahn Books, USA.

Womack, J. P., Jones, D. T., Roos, D., 1990. The Machine That Changed the World : The Story of Lean Production. Harper Collins Publishers, New York.

Woodrow Eckard, Jr, E., September 1979. A note on the empirical measurement of vertical integration. Journal of Industrial Economics 28 (1), 105-107.

Zaghini, E., 1967. Una nota sui subsistemi di Sraffa. Studi Economici 22, 290305 . 